\title{
COVID-19 crisis management in Luxembourg: Insights from an epidemionomic approach
}

\author{
Michał Burzyński $^{\mathrm{a}}$, Joël Machado ${ }^{\mathrm{a}}$, Atte Aalto ${ }^{\mathrm{b}}$, Michel Beine ${ }^{\mathrm{c}}$, Jorge Goncalves ${ }^{\mathrm{b}}$, Tom Haas ${ }^{\mathrm{d}}$, \\ Françoise Kemp $^{\mathrm{b}}$, Stefano Magni ${ }^{\mathrm{b}}$, Laurent Mombaerts ${ }^{\mathrm{b}}$, Pierre Picard ${ }^{\mathrm{c}}$, Daniele Proverbio ${ }^{\mathrm{b}}$, \\ Alexander Skupin ${ }^{\mathrm{b}}$, Frédéric Docquier ${ }^{\mathrm{a}}{ }^{*}$ \\ ${ }^{\text {a }}$ Luxembourg Institute of Socio-Economic Research, Luxembourg \\ ${ }^{\mathrm{b}}$ University of Luxembourg, Luxembourg Centre for Systems Biomedicine, Luxembourg \\ ${ }^{\mathrm{c}}$ University of Luxembourg, Department of Economics and Management, Luxembourg \\ ${ }^{\mathrm{d}}$ STATEC, Luxembourg
}

\section{A R T I C L E I N F O}

\section{JEL classification:}

E37

I18

Keywords:

Growth

Productivity

Coronavirus

Lockdown

Public health

\begin{abstract}
A B S T R A C T
We develop an epidemionomic model that jointly analyzes the health and economic responses to the COVID-19 crisis and to the related containment and public health policy measures implemented in Luxembourg. The model has been used to produce nowcasts and forecasts at various stages of the crisis. We focus here on two key moments in time, namely the deconfinement period following the first lockdown, and the onset of the second wave. In May 2020, we predicted a high risk of a second wave that was mainly explained by the resumption of social life, low participation in large-scale testing, and reduction in teleworking practices. Simulations conducted 5 months later reveal that managing the second wave with moderately coercive measures has been epidemiologically and economically effective. Assuming a massive third (or fourth) wave will not materialize in 2021, the real GDP loss due to the second wave will be smaller than 0.4 percentage points in 2020 and 2021.
\end{abstract}

\section{Introduction}

The COVID-19 pandemic has affected people's health and economic indicators all around the globe. Focusing on Luxembourg's economy and workers from neighboring regions (representing about one half of Luxembourg's labor force), we develop an epidemionomic model that combines an extended Input-Output economic block with a multi-sector SIR epidemiological block, and use it to analyze the public health and economic effects of the COVID-19 crisis week after week throughout the years 2020 and 2021. The Input-Output structure allows us to account for the cascading responses to non-pharmaceutical interventions, due to inter-industry and inter-country linkages. ${ }^{1}$ The SIR epidemiological block accounts for interactions between transmission rates on the job in each industry (influenced by employment rates), and transmission rates outside the labor market (at school and in social life, in Luxembourg and in its contiguous regions). Our model is the product of a collaborative effort involving economists and epidemiologists from various institutions based in Luxembourg. It has been used to produce nowcasts and forecasts to assist decision makers at various stages of the crisis.

In particular, we focus here on two key moments in time. The first one is the deconfinement period following the first lockdown (May 2020). As virus transmission rates had reached very low levels in Luxembourg, this seemed an ideal time for lifting containment measures. The model was used to highlight the risk of a rebound in the infection curve and to identify appropriate accompanying measures. The second moment brings us back to October 2020, when the COVID-19 second wave was hitting much of Europe. It is thus with a weary sense of déjà vu that Luxembourg's citizens were impacted by new packages of restrictions implemented to contain the virus. The specter of a reconfinement hanged over the economy. Our model was used to compare the implications of moderately and highly coercive sanitary measures, and to assess the macroeconomic impact of the second wave.

\footnotetext{
* Corresponding author.

E-mail address: frederic.docquier@liser.lu (F. Docquier).

1 Baldwin and Weder di Mauro (2020) argued: "this virus is as economically contagious as it is medically contagious." As the production of basic and intermediate

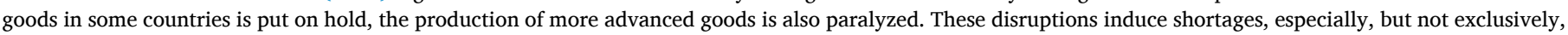
in the healthcare sector, and result in surges in prices and competition between consumers and between countries.
} 
The key principle of our model is that it treats economic and epidemiological trends as interdependent, which is justified for several reasons. Firstly, it has been abundantly documented that non-pharmaceutical measures implemented at various stages of the crisis have affected public health and economic indicators jointly. In particular, lockdown and social distancing measures were necessary to flatten the infection curve and avoid a collapse of the health care system, at the cost of generating sizeable cuts in economic output. ${ }^{2}$ Secondly, after several phases of generalized or partial lockdown, policymakers implemented gradual measures to restart the economy. Lifting containment measures induces changes in employment which in turn, revive on-the-job interactions between workers as well as between workers and customers. Depending on PCR testing policies, contact tracing, social distancing, hygiene and prevention measures at the workplace and in social activities, these interactions impacted the propagation of the virus within the country as well as in the cross-border regions. In turn, changes in infection rates in the neighboring regions affect the number of workers available for the labor market and potential employment levels. ${ }^{3}$

Uncertainty around the scale of these interactions and around the effectiveness of lockdown and deconfinement plans has always been substantial. We use our epidemionomic model to produce nowcasts and forecasts of the effects of the crisis and related containment policies, refining the estimates provided by OECD (2020) and RECOVid (2020) and producing results by period of one week throughout the years 2020 and 2021. Our main findings are the following. During the first deconfinement period, we were relatively optimistic that the restarting of lockdown industries per se would not generate a relapse of the pandemic if teleworking practices could be maintained and large-scale testing is well implemented. By contrast, we argued that bringing teleworkers back to the workplace and, perhaps more importantly, the resumption of social life were likely to generate a rebound in the infection curve. Five months later, almost at the onset of the second wave, we were relatively optimistic about the effectiveness of moderately coercive sanitary measures implemented in 2020Q4 and 2021Q1. We estimate that the management of the second wave translates into a GDP loss that is smaller than 0.4 percentage point in the years 2020 and 2021. Our scenario is still valid today and compatible with the vaccination campaign. If Luxembourg can escape a massive third and/or fourth wave - a threat linked to the propagation of new variants of the virus - in the post-Summer period, real GDP growth should be around 3.7\% in 2021, a level that is slightly inferior to the long-run trend.

We contribute to a recent and fast-growing literature linking public health and economic responses to the COVID-19 crisis. Part of the literature focuses on the dynamics of the disease, including the role of social-distancing (Greenstone and Nigam, 2020) and the quantification of the work that can be done from home in order to slow down the spread of the virus (see e.g., Barbieri et al., 2020; Koren and Peto, 2020; Dingel and Neiman, 2020; Depalo, 2021; Milani, 2021). An increasing number of papers adds epidemiological blocks to macro-economic models to evaluate the cost of the lockdown and different restarting

\footnotetext{
${ }^{2}$ Some authors have seen lockdown measures as resulting from a tradeoff between public health and economic objectives (Barro et al., 2020; Gourinchas, 2020). This tradeoff is much more ambiguous than it is apparent as the recession could have been deeper without the lockdown, as evidenced from the 1918 Spanish flu (Correia et al., 2020). It is hard to identify whether the measures implemented to curb the infection curves contributed to increase or decrease confidence in the economic system. A severe public health crisis alone could have generated panic and (potentially drastic) changes in individual behaviors. Many economic crises were associated with panics from depositors or from the banking sector.

3 According to Facebook data, commuting flows and business travels represent $99 \%$ of cross-border movements traffic in normal times (Docquier et al., 2021). Things might be different during the vacation periods. Although the number of holiday makers has been smaller than usual in 2020, we ignore the role of these moves in the contamination process due to absence of data.
}

strategies (Atkeson, 2020; Alvarez et al., 2020; Jones and Philippon, 2020; Berger et al., 2020; Bonacini et al., 2021a). For example, Eichenbaum et al. (2020) extend the canonical epidemiological model to study how endogenous consumption and labor supply decisions of utility-maximizing agents affect contagion. The competitive equilibrium of their model is not socially optimal because infected individuals do not internalize how their actions amplify the spread of the virus. More similar to us, Fadinger and Schymik (2020) use an input-output model calibrated on Germany to evaluate the impact of work-from-home (henceforth referred to as teleworking) on infection risk and output at the regional level. Simulating a confinement where production is done exclusively by workers who can work-from-home, they find that confinement reduces labor supply by $58 \%$ and implies a weekly GDP loss equivalent to $1.6 \%$ of the annual GDP. Barrot et al. (2020) calibrate a standard network model using French input-output linkages. These two papers are similar in spirit to our strategy but our model also accounts for other important ingredients such as teleworking, parental leaves, testing and quarantining polices, etc. Moreover, our epidemiological block accounts for the spread of the virus outside the workplace in addition to differential infection rates of cross-border workers, a specificity of the Luxembourgish labor market.

The remainder of this paper is organized as following. Section 2 describes the epidemionomic model and its parameterization. Health and economic effects of the COVID-19 crisis and lockdown measures and restarting scenarios are investigated in Section 3. Section 4 concludes.

\section{An epidemionomic model for Luxembourg}

We develop a model that links the economic and epidemiological aspects of the COVID-19 crisis. Individuals and firms' behaviors are not micro-founded, but embedded in scenarios. We parameterize it on Luxembourg's economy and population - accounting for cross-border labor movements between Luxembourg and its contiguous regions and use it to nowcast and forecast the public health and economic effects of the pandemic and related containment measures at different key stages of the crisis. The model has a weekly structure, and assumes that one week corresponds to the time of delivery of intermediate inputs from one industry to another.

\subsection{Economic structure}

The COVID-19 crisis has required total or partial lockdown measures implemented in several industries (accommodation and food services; arts, entertainment and recreation services; construction; wholesale, retail trade and repair services; and to a lesser extent in the manufacturing industry; transportation and storage services; real estate services). Given intersectoral linkages, these lockdown measures have gradually "contaminated" the other sectors of the economy, leading to cascading effects. Similarly, lifting economic containment measures induces ripple effects on the rest of the economy. Large benefits from deconfinement arise in industries exhibiting the greater linkages with lockdown sectors, while simultaneously not suffering from disrupted global supply chains.

To account for intersectoral linkages, we develop here an extended Input-Output (I/O) model that accounts for both demand-side and supply-side mechanisms. This extended I/O framework is intended to characterize the functioning of the economy with fixed prices, fixed capital stocks, fixed technology and fixed workforce size by industry (i. e., no intersectoral mobility). Industries are denoted by $i=1, \ldots, I$. Our model distinguishes between nineteen industries, listed in Table 1. Before adding the time dimension, we first focus on the (stationary) equilibrium of the model.

Standard I/O model. The standard I/O model ignores supply-side constraints and assumes that each sector's output is determined by total demand - demand of intermediate inputs by other sectors, and demand for final goods by domestic and foreign actors. Typically, the 
total sales of industry $i\left(X_{i}^{d}\right)$ are given by:

$X_{i}^{d}=\sum_{j} X_{\mathrm{ij}}+D_{i}+E_{i}$,

where $X_{i, j}$ is the demand for intermediate inputs by industry $j, D_{i}$ is the domestic (Luxembourgish) demand for final goods, and $E_{i}$ is the demand for exports.

The demand for intermediate inputs by industry $j$ is assumed to be proportional to the total sales of that industry. We thus have $X_{\mathrm{ij}}=a_{\mathrm{ij}} X_{j}^{d}$, where the $a_{\mathrm{ij}}$ 's represent constant technological coefficients. Eq. (1) can be rewritten as:

$X_{i}^{d}=\sum_{j} a_{\mathrm{ij}} X_{j}^{d}+D_{i}+E_{i}$

which links the total sales of industry $i$ to the total sales of all other industries.

Using matrix notations and denoting the matrix of technological coefficients by $A$, this gives $X^{d}=\mathrm{AX}^{d}+D+E$ which represents a system of $I$ equations. The well-known solution of the standard $\mathrm{I} / \mathrm{O}$ model is given by $X^{d}=(1-A)^{-1}(D+E)$. In this framework, a positive demand shock in industry $i$ generates a direct increase in output. This increases the demand for intermediate inputs addressed to the other sectors, which in turn increase their own demand for intermediate inputs and thereby generate indirect effects on the economy. The exact opposite mechanism arises when the economy is subject to a negative demand shock. The larger the linkages with the other sectors (i.e., the larger the $a_{\mathrm{ij}}$ 's), the larger the total effect on the economy.

Non-binding supply-side. The underlying supply side of the standard I/O model is governed by the following relationship ${ }^{4}$ :

$X_{i}^{d}=\sum_{j} X_{\mathrm{ji}}+Y_{i}+M_{i}$,

where $X_{i}^{d}$ is the amount produced in industry $i$. On the right-hand side, the first term of the sum represents the value of domestic intermediate inputs (such that $X_{\mathrm{ji}}=a_{\mathrm{ji}} X_{i}^{s}$ ), $Y_{i}$ is the value added in industry $i$, whose production requires using $K_{i}$ units of physical capital and $L_{i}$ workers (i. e., $\left.Y_{i}=F\left(K_{i}, L_{i}\right)\right)$, ${ }^{5}$ and $M_{i}$ is the demand for foreign inputs (i.e., imports). As local intermediate inputs, imports are proportional to total sales $\left(M_{i}=m_{i} X_{i}^{d}\right)$. Hence, Eq. (2) determines the equilibrium level of sales in all industries $\left(X_{i}^{d}\right)$, and Eq. (3) determines how sales revenue is distributed among domestic and foreign suppliers of intermediate inputs, workers and capital owners.

For a given stock of physical capital $\left(K_{i}\right)$ and a given supply of labor $\left(L_{i}^{s}\right)$ in each industry $i$, the maximal value added can be expressed as $Y_{i}^{s}=$ $F\left(K_{i}, L_{i}^{s}\right)$. The full-employment condition in industry $i$ is given by:

$X_{i}^{s}=\left[\sum_{j} a_{\mathrm{ji}}+m_{i}\right] X_{i}^{s}+Y_{i}^{s}=\frac{Y_{i}^{s}}{1-\sum_{j} a_{\mathrm{ji}}-m_{i}}$,

which implies that total sales and value added in each industry $i$ are linked by a relation of proportionality (whether the full-employment condition holds or not).

The implicit assumption of the standard I/O model is that $X_{i}^{d}<X_{i}^{s}$ in all sectors, or equivalently, $Y_{i}^{d}<Y_{i}^{s}$ and $L_{i}^{d}<L_{i}^{s}$. ${ }^{6}$ Hence, firms can respond to the rising demand from the other sectors and from final

\footnotetext{
${ }^{4}$ Eq. (3) corresponds to a column of the I/O matrix, whereas Eq. (2) corresponds to a row.

${ }^{5}$ In the Cobb-Douglas case, we have $Y_{i}=B_{i} K_{i}^{1-\alpha_{i}} L_{i}^{\alpha_{i}}$ where $\alpha_{i}$ is the labor income share in industry $i$, and $B_{i}$ denotes total factor productivity.

${ }^{6}$ Another implicit assumption is that $L_{i}^{s}$ is smaller than the optimal level of employment $L_{i}^{*}$ (corresponding to a value added of $Y_{i}^{*}=F\left(K_{i}, L_{i}^{*}\right)$ and a level of total sales of $X_{i}^{*}$ ). The latter level is determined by profit maximization.
}

consumers by producing more. As $K_{i}$ is fixed, the only variable of adjustment that firms can use is $L_{i}$, the level of employment. When supply follows demand, firms adjust the level of employment to meet total demand for their product. Hence, $L_{i}^{d}=F^{-1}\left[X_{i}^{d}\left(1-\sum_{j} a_{\mathrm{ji}}-m_{i}\right)\right]$. When demand increases, firms in industry $i$ increase their value added $\left(Y_{i}^{d}\right)$ and their imports $\left(M_{i}\right)$ without constraints to meet demand for their goods. The supply-side plays no role, except that it determines how revenues are distributed between capital owners, workers, domestic and foreign suppliers of intermediate goods.

Binding supply-side constraints. When modeling the effect of the COVID-19 crisis and of lockdown measures, we need to enrich the standard model with binding supply-side constraints. First, containment measures reduce the permitted level of employment in lockdown industries. Second, some workers are infected by COVID-19 and cannot supply labor. Third, in addition to infection, school closures imply that many workers are forced to take parental leave. Fourth, disrupted global value chains can be such that the required amount of imported intermediate goods $\left(m_{i} X_{i}^{d}\right)$ is not available on the market. In Luxembourg, firms did not report shortages of foreign intermediate inputs during the COVID-19 crisis. $^{7}$ However, lockdown and sanitary measures have drastically reduced the maximal level of employment during the lockdown $\left(L_{i}^{s}\right)$, and this has affected the maximal levels of value added $Y_{i}^{s}$ and of sales. We will explain how the level of $L_{i}^{s}$ is linked to lockdown and epidemiological conditions in the next section.

Starting from the pre-crisis stationary equilibrium, our economic block can be used to simulate the economic effect of the crisis and resulting lockdown measures (i.e., constraints on $L_{i, t}^{s}$ and $Y_{i, t}^{s}$ ) on activity. Two important ingredients govern our simulated trends. First, we assume that each iteration of the I/O matrix takes one week of time. Final demand is met instantaneously when supply constraints allow for it, while supplying intermediate inputs involve a delivery delay of one week. We thus include a time subscript $t$ into the notations. Second, at each iteration, we combine demand and supply constraints, allowing the condition $X_{i, t}^{d}<X_{i, t}^{s}$ to be violated in some industries.

The dynamics of the extended I/O model with supply-side constraints are now characterized by:

$X_{i, t}=\min \left[X_{i, t}^{s}, \sum_{j} a_{\mathrm{ij}} \min \left(X_{j, t-1}^{d}, X_{j, t-1}^{s}\right)+D_{i, t}+E_{i, t}\right]$

Given the parameters of the Luxembourg I/O table and the economic/health shocks induced by COVID-19, the simulated solution of this model determines the endogenous production regime of each industry (excess supply or constrained supply capacity) as well as industry-specific multiplier effects. For industries in excess supply capacity, demand determines the total level of sales which, in turn, determines the level of employment and value added. For industries in constrained supply capacity, the maximal level of employment determines the value added which in turn, determines the total amount of sales. As stated above, the existence of supply constraints induces a disciplined and sizeable cut in output. Binding supply constraints also limit the magnitude of the I/O multiplier. This slows down the recovery when some confined sectors are restarted or when final demand increases.

\subsection{Epidemiological structure}

The epidemiological block consists of a multi-sector SIR compartmental model governing the shares of susceptible, infected and recovered people from 78 socio-demographic groups. These include Luxembourgish students and retirees (2 groups of inactive nationals), as

\footnotetext{
${ }^{7}$ According to the (unpublished) survey launched by the Chamber of Commerce during the first lockdown.
} 
well as workers from 4 countries of residence who can be employed in 19 industries (listed in Table 1, corresponding to 76 groups of workers). In sum, we have:

- Six age/origin groups (denoted by superscript $a$ ): students (with $a=$ $y$ for young), workers (with superscript $a \in o$, denoting the country of residence of workers) and retirees people (with $a=r$ ). For workers, we distinguish four countries: $o=(L, F, G, B)$ for Luxembourg, France, Germany and Belgium. Students and retirees are all living in Luxembourg. We thus have six age/origin groups, $a=$ $(y, L, F, G, B, r)$.

- Twenty-one sectors of the society (denoted by $i=0,1, \ldots, I, I+1$ ) in which within-group interactions take place: schools are denoted by sector $i=0$ and relate to group $y$ only, 19 industries are denoted by sectors $i=1, \ldots, I$ (in line with the notations of the previous section) and relate to groups $o=(L, F, G, B)$ only, and the old-age sector is denoted by $i=I+1$ ( $=20$ in our case) and relates to group $r$ only (it includes retirement homes and social activities for retirees).

The total population of each socio-demographic group is denoted by $N_{i}^{a}$ and is assumed to be constant over time. Our SIR model by construction ignores deaths. ${ }^{8}$ At time $t$, the population of each group is divided into $S_{i, t}^{a}$ susceptible, $I_{i, t}^{a}$ infected, and $R_{i, t}^{a}$ recovered. The group of infected includes $A_{i, t}^{a} \equiv \theta I_{i, t}^{a}$ infected and asymptomatic people $(\theta<1)$. Combining all possible categories, we obtain 312 groups (78 sociodemographic groups times 4 possible health status).

Virus transmission rates in sector $i$ (i.e., on the job for workers, at school for students, and in the old-age sector for retirees) and in the place of residence (where all groups can interact) are endogenous. The contamination process depends on the quantity of within-group interactions (influenced by the fraction of time spent in one's own sector, $e_{i, t}$ ) and between-group interactions (determined by $1-e_{i, t}$ ). As explained below, we refer to the extensive margin mechanism when discussing the role of time allocation. The contamination process also depends on the sector-specific transmission rates, which are influenced by sanitary policies as well as by the number of people interacting, as explained later. We refer to the intensive margin mechanism when discussing the latter effect. The population dynamics in the 312 groups are governed by:

$$
\left\{\begin{array}{l}
S_{i, t+1}^{a}=S_{i, t}^{a}-e_{i, t}^{a} b_{i, t} \frac{S_{i, t}^{a} \sum_{a} I_{i, t}^{a}}{\sum_{a} N_{i}^{a}}-\left(1-e_{i, t}^{a}\right) \beta_{t}^{a} S_{i, t}^{a} \bar{l}_{t}^{a}, \\
I_{i, t+1}^{a}=I_{i, t}^{a}+e_{i, t}^{a} b_{i, t} \frac{S_{i, t}^{a} \sum_{a} I_{i, t}^{a}}{\sum_{a} N_{i}^{a}}+\left(1-e_{i, t}^{a}\right) \beta_{t}^{a} S_{i, t}^{a} \bar{l}_{t}^{a}-G_{i, t}^{a}, \\
A_{i, t+1}^{a}=\theta I_{i, t+1}^{a}, \\
R_{i, t+1}^{a}=R_{i, t}^{a}+G_{i, t}^{a},
\end{array}\right.
$$

where $b_{i, t}$ is the within-sector virus transmission rate in sector $i$ in Luxembourg, $\beta_{t}^{a}$ is the virus transmission rate outside the sector (in family life, leisure, etc.) in the country of residence of group $a, \bar{i}_{t}^{a}$ is the country-wide average proportion of infected people in the population of the country of residence, and $G_{i, t}^{a}$ is the flow of recovered in group $a$ and

\footnotetext{
8 Assuming deaths are proportional to the number of infected retirees would not change significantly the results. As of July 1st 2021, the country has recorded 818 deaths due to COVID-19, representing $0.14 \%$ of its population only. See Favero et al. (2020) for a more complex approach involving age-specific lethality rates.
}

in week $t$. These parameters are defined over a period of one week in our model. Before the vaccine is available, we assume that immunity is obtained after having been infected and is permanent. ${ }^{9}$

In the case of COVID-19, most infected people recover after 10 days on average. In a model with a daily structure, we would define the number of recovered as the number of new contagious cases nine days before. Here, the weekly structure of our model implies that the flow of recovered during week $t$ is a weighted sum of the flow of contagious cases in weeks $t-1$ and $t-2$. Following analytical developments in Appendix A of Burzynski et al. (2020), the weekly flows of recovered group $a$ and industry $i$ during period $t$ can be approximated by a weighted sum of the flows of new infections at time $t-2$ and $t-1:^{10}$

$$
\begin{aligned}
G_{i, t}^{a}=\frac{2}{7}\left[e_{i, t-2}^{a} b_{i, t-2} \frac{S_{i, t-2}^{a} \sum_{a} I_{i, t-2}^{a}}{\sum_{a} N_{i}^{a}}+\left(1-e_{i, t-2}^{a}\right) \beta_{t-2}^{a} S_{i, t-2}^{a} \bar{i}_{t-2}^{a}\right] \\
+\frac{5}{7}\left[e_{i, t-1}^{a} b_{i, t-1} \frac{S_{i, t-1}^{a} \sum_{a} I_{i, t-1}^{a}}{\sum_{a} N_{i}^{a}}+\left(1-e_{i, t-1}^{a}\right) \beta_{t-1}^{a} S_{i, t-1}^{a} \bar{i}_{t-1}^{a}\right]
\end{aligned}
$$

Turning our attention to transmission rates, they depend on the frequency of contacts between infected and susceptible people within each sector of the society. We assume that sick and symptomatic workers/students/retirees self-isolate as soon as they feel the symptoms. This is a reasonable assumption in Luxembourg as medical doctors received the means to quarantine potentially infected people and to provide PCR tests throughout the pandemic (even at the early stage). As symptoms are felt a few days after becoming infectious (2.5-3 days, Liu et al. (2020)), a fraction $\mu_{i, t}$ of symptomatic people maintain within-sector interactions while being contagious if PCR testing is not performed on a daily basis. Some individuals are asymptomatic during the whole cycle of the disease and never self-isolate. A (greater) fraction $\bar{\mu}_{i, t}^{a}$ of asymptomatic individuals maintain within-sector interactions. The fractions $\left(\mu_{i, t}, \bar{\mu}_{i, t}^{a}\right)$ depend on the efficiency and frequency of PCR testing as well as contact tracing. Within-sector and out-of-sector transmission rates can be expressed as:

$\left\{\begin{array}{l}b_{i, t}^{a}=\bar{b}_{i} \bar{\rho}_{i, t} e_{i, t}^{\chi_{i}}\left[(1-\theta) \mu_{i, t}+\theta \bar{\mu}_{i, t}^{a}\right], \\ \beta_{t}^{a}=\bar{\beta}^{a} \rho_{t}^{a},\end{array}\right.$

which allows to highlight the main determinants of virus propagation:

- Within-sector transmission rates depend on the average number of contacts per person and per unit of time, and on the probability that infected people have contacts with susceptible subjects. Infected people's probability to have contacts with susceptible subjects depends on the probability of a contagious individual to maintain interactions with his peers, which is given by $\left[(1-\theta) \mu_{i, t}+\theta \bar{\mu}_{i, t}^{a}\right]$ in Eq. (8). This probability depends on the share of asymptomatic cases $(\theta)$

\footnotetext{
9 The duration of immunity from COVID-19, if any, is not determined yet. The model predictions are thus valid for time periods that do not exceed the duration of the acquired immunity.

${ }^{10}$ We numerically show in Appendix A of Burzynski et al. (2020) that predicting the weekly flow of recovered using Eq. (7) improves the predictive power of the model in comparison with a probabilistic model relying on a constant recovery rate (i.e., $G_{i, t}^{a}=g \times L_{i, t}^{\mathrm{OI}}$ ). The reason is that, contrary to the flow of new infections within the week, the total stock of contagious people $\left(I_{i, t}^{a}\right)$ has no reason to be distributed uniformly over the 10 daily contagious cohorts: this stock increases rapidly during the first phase of the pandemic (i.e., when the number of COVID-19 cases increases rapidly), and decreases fast after the peak of the infection curve has been reached.
} 
as well as on testing and tracing measures implemented to isolate infected workers $\left(\mu_{i, t}, \bar{\mu}_{i, t}\right)$.

- The number of contacts per unit of time within sector $i$ is expressed as the product of $\bar{b}_{i}$, a sector-specific parameter that reflects working conditions in normal times (i.e., physical proximity, exposure to disease, age group, etc.), by $\rho_{i, t}$, a variable that can be normalized to unity at the beginning of the pandemic, and that captures prevention and physical distancing measures implemented in the sector. In addition, physical distancing might partly depend on the density of people in the sector (influenced by $e_{i, t}$ ), a mechanism that is referred to as the intensive-margin effect of employment on transmission rates. A potential specification is $\rho_{i, t}=\bar{\rho}_{i, t} e_{i, t}^{\chi_{i}}$, where $\chi_{i}$ is the elasticity of physical distancing to the within-sector density of people in sector $i$. This elasticity varies across sectors as a function of working conditions (proximity between workers or with customers, share of outdoor activities, etc.). The other variable $\bar{\rho}_{i, t}$ captures the effect of sanitary measures.

- Similarly, in all regions of residence, the number of contacts per unit of time spent outside the sector can be expressed as the product of $\bar{\beta}^{a}$ by $\rho_{t}^{a}$. Hence, two regions or countries sharing different economic and socio-demographic characteristics exhibit different levels of $\bar{\beta}^{a}$, while $\rho_{t}^{a}$ is governed by nation-wide or local social distancing and prevention measures (as in Brodeur et al., 2020; Qiu and Chen, 2020).

To close the epidemiological block, we consider that the trajectories of $\bar{i}_{t}^{a}$ are exogenous outside Luxembourg (i.e., for $o=(G, F, B)$ ), whereas the trajectory of $\bar{i}_{t}^{L}$ is endogenous and given by the average of all groups of Luxembourgish population:

$\bar{i}_{t}^{L}=\frac{\sum_{i} \sum_{a=(y, L, r)} I_{i, t}^{a}}{\sum_{i} \sum_{a=(y, L, r)} N_{i}^{a}}$.

\subsection{Epidemionomic interdependencies}

We now highlight interdependencies between the economic and epidemiological blocks. First, sanitary policy measures and the evolution of the number of infected workers influence the number of workers available in industry $i=1, \ldots, I$ in Luxembourg. Labor supply in COVID19 times can be expressed as:

$L_{i, t}^{s}=\sum_{a} \phi_{i, t}\left(1-\lambda_{i, t}^{a}\right)\left(S_{i, t}^{a}+R_{i, t}^{a}+\mu_{i, t}(1-\theta) I_{i, t}^{a}+\bar{\mu}_{i, t} \theta I_{i, t}^{a}\right)$,

where $\phi_{i, t}$ is the lockdown constraint on employment $\left(\phi_{i, t}<1\right.$ in lockdown industries and $\phi_{i, t}=1$ in the others), $\lambda_{i, t}^{a}$ is the share of workers on parental leave, equal to the share of parents with young children when schools are closed in sector $a$, and zero if schools fully re-open. A total lockdown would imply that $\phi_{i, t}=0$. In practice, a minimal level of postlockdown activity is observed in all sectors, either because the lockdown applies to a sub-sector only, or because entrepreneurs find ways to maintain a certain level of output by re-orienting their activity (e.g., restaurants providing catering services with delivery at home). As $\mu_{i, t} \leq 1$, Eq. (10) clearly shows that a rise in the number of infected workers decreases the supply of labor and potentially influences the level of economic activity. In the same vein, PCR testing and quarantine measures allow identifying asymptomatic cases and reducing $\bar{\mu}_{i, t}$.

Reciprocally, the evolution of employment in each industry governs the time allocation of each type of individual and influences transmission rates through the extensive and intensive margins. Within each sector of the society, the rate of presence (at the workplace, at school or in the old-age sector) can be expressed as:

$$
\left\{\begin{array}{l}
e_{0, t}=\varepsilon \mathbf{1}_{t}^{\text {School }} \\
e_{i, t}=\varepsilon\left(1-\tau_{i, t}^{a}\right) \frac{\min \left(L_{i, t}^{d}, L_{i, t}^{s}\right)}{\sum_{a} N_{i, t}^{a}} \text { foralli }=1, \ldots, \mathrm{I}, \\
e_{I+1, t}=\frac{\varepsilon}{2}
\end{array}\right.
$$

where $\varepsilon \leq 1$ is a constant capturing the fact that employed workers and students do not spend one hundred percent of their time at the workplace or at school. ${ }^{11}$ For students, $\mathbf{1}_{t}^{\text {School }}$ is a dummy equal to one when schools are open, and zero otherwise. In the productive sectors $(i=1, \ldots$, $I)$, the second term, $\min \left(L_{i, t}^{d}, L_{i, t}^{s}\right) / \sum_{a} N_{i, t}^{a}$ is the employment rate of group $a$ in industry $i$. When the employment rate is smaller than unity, we assume that employees present at the workplace are randomly drawn from the industry-specific labor force, which means that employment rates are identical across countries of residence for active workers. In addition, $\tau_{i, t}^{a}$ denotes the share of employees in situation of teleworking in sector $i$, and do not contribute to virus transmission at the workplace (Papanikolaou and Schmidt, 2020a,b; Favero et al., 2020; Mongey et al., 2020). These rates are highly heterogeneous across industries and skill groups, which can reinforce labor market inequalities in lockdown times (Bonacini et al., 2021a,b; Palomino et al., 2020). In Luxembourg, the high replacement rate (i.e., $80 \%$ of the pre-crisis income) offered to workers in partial unemployment, sick leave and parental leave has prevented inequality from increasing (O'Donoghue et al., 2021). In the old-age sector, we assume that retirees spend half of their time interacting with retirees, and half of their time interacting with other groups.

In our setting, lifting economic containment measures in industry $i$ implies an increase in the rate of presence at the workplace $\left(\Delta e_{i, t}\right)$ and a resulting rise in the weekly flow of infected workers that is governed by:

$\frac{\mathrm{dI}_{i, t+1}^{a}}{\mathrm{de}_{i, t}}=\underbrace{\left[b_{i, t} \frac{S_{i, t}^{a} \sum_{a} I_{i, t}^{a}}{N_{i, t}^{a}}-\beta_{t}^{a} S_{i, t}^{a} \bar{l}_{t}^{a}\right]}_{\text {Extensive margin }}+\underbrace{\chi_{i} b_{i, t} \frac{S_{i, t}^{a} \sum_{a} I_{i, t}^{a}}{N_{i, t}^{a}}}_{\text {Intensive margin }}$.

Eq. (12) shows that shocks in employment rates and teleworking practices influence the infection curve through two mechanisms. Changes in workers' presence rate mechanically influence the flow of new infections through the extensive margin - changes in time spent on the job, where exposition to the disease differs from that prevailing in the place of residence - and through the intensive margin - changes in physical distancing and transmission rates on the job due to the higher density of employees. If $\chi_{i}=0$, changes in employment rates have no effect on transmission rates (at the intensive margin), although they affect the weight given to $b_{i, t}$ relatively to $\beta_{t}^{a}$ in Eq. (6); this is the first term of the derivative above. In such a setting, the lockdown-driven decrease in $b_{i, t}$ can be considered as permanent. In contrast, if $\chi_{i}>0$, part of that decrease in transmission rate is lost when workers get back to their workplace; this is the second term of the derivative.

\subsection{Parameterization}

Our epidemionomic model is an evolving tool that aims to promptly deliver initial results at first, and then increasingly more refined results and predictions as the set of available data on socioeconomic variables and leading indicators increases. Hence, our inputs and parameters have been frequently updated throughout the course of the crisis. Our

\footnotetext{
${ }^{11}$ When workers are fully employed, the daily amount of time spent interacting with other workers is shared between a fraction $\varepsilon$ on-the-job, and a fraction $(1-\varepsilon)$ in the place of residence. The choice of $\varepsilon$ has little influence on the results as it mainly determines the scale of transmission rates.
} 
quantitative analysis below focuses on two key moments in time, the end of the first lockdown (starting in April 2020), and the onset of the second wave (October 2020). We explain here how the model has been (re-) parameterized at these two key stages of the crisis.

Parameterization of the economic block. Our economic block includes a set of parameters that have not been updated during the crisis. It is calibrated to match the I/O table of 2017, which includes the 19 industries at the one-digit level, as reported in Table 1. The largest industries are 'Financial and insurance services' (28.4\% of GDP in normal times), 'Wholesale and retail trade' (9.9\%) and 'Real estate services $(8.7 \%)$; the smallest industries are 'Mining and quarrying' (less than $0.1 \%)$ and 'Agriculture, forestry and fishing' $(0.3 \%)$. The I/O table defines the matrix of technical coefficients $\left(a_{\mathrm{ij}}\right)$ and provides initial values for the industry-specific levels of sales $\left(X_{i, 0}\right)$, value added $\left(Y_{i, 0}\right)$, employment $\left(L_{i, 0}\right)$, stock of physical capital $\left(K_{i, 0}\right)$, imports $\left(M_{i, 0}\right)$, exports $\left(E_{i, 0}\right)$ and domestic demand $\left(D_{i, 0}\right)$. Social security (IGSS, Inspection générale de la sécurité sociale) and SILC (Statistics on Income and Living

Table 1

Macroeconomic shocks by industry (as of April 1st, 2020).

\begin{tabular}{|c|c|c|c|c|c|c|}
\hline & $\begin{array}{l}(1) \\
\lambda_{i, t}^{a}\end{array}$ & $\begin{array}{l}(2) \\
\phi_{i, t}\end{array}$ & $\begin{array}{l}(3) \\
u_{i, t}^{a}\end{array}$ & $\begin{array}{l}(4) \\
\tau_{i, t}^{a}\end{array}$ & $\begin{array}{l}\text { (5) } \\
\frac{\Delta E_{i, t}}{E_{i, t}}\end{array}$ & $\begin{array}{l}(6) \\
\frac{\Delta D_{i, t}}{D_{i, t}} \\
\end{array}$ \\
\hline $\begin{array}{l}\text { Agric., forestry, } \\
\text { fishing }\end{array}$ & 0.068 & 0.000 & 0.159 & 0.194 & 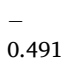 & $\begin{array}{l}- \\
0.400\end{array}$ \\
\hline Mining, quarrying & 0.068 & 1.000 & 0.089 & 0.372 & $\begin{array}{l}- \\
0.200\end{array}$ & $\begin{array}{l}- \\
0.200\end{array}$ \\
\hline $\begin{array}{l}\text { Manufactured } \\
\text { products }\end{array}$ & 0.068 & 1.000 & 0.367 & 0.313 & $\begin{array}{l}- \\
0.200\end{array}$ & $\begin{array}{l}- \\
0.200\end{array}$ \\
\hline Electricity, gas, steam & 0.068 & 1.000 & 0.350 & 0.543 & $\begin{array}{l}- \\
0.991\end{array}$ & $\begin{array}{l}- \\
0.400\end{array}$ \\
\hline $\begin{array}{l}\text { Water, sewerage, } \\
\text { waste }\end{array}$ & 0.068 & 1.000 & 0.184 & 0.322 & $\begin{array}{l}- \\
0.498\end{array}$ & $\begin{array}{l}- \\
0.400\end{array}$ \\
\hline Construction & 0.089 & 0.053 & 0.224 & 0.060 & $\begin{array}{l}- \\
0.200\end{array}$ & $\begin{array}{l}- \\
0.200\end{array}$ \\
\hline $\begin{array}{l}\text { Wholesale, retail, } \\
\text { repair }\end{array}$ & 0.066 & 0.535 & 0.388 & 0.060 & $\begin{array}{l}- \\
0.200\end{array}$ & $\begin{array}{l}- \\
0.200\end{array}$ \\
\hline Transport, storage & 0.079 & 1.000 & 0.263 & 0.285 & $-\overline{0.200}$ & $\begin{array}{l}- \\
0.200\end{array}$ \\
\hline Accommodation, food & 0.075 & 0.235 & 0.679 & 0.103 & $\begin{array}{l}- \\
0.400\end{array}$ & $\begin{array}{l}- \\
0.400\end{array}$ \\
\hline Information, comm. & 0.093 & 1.000 & 0.105 & 0.856 & $\begin{array}{l}- \\
0.482\end{array}$ & $\begin{array}{l}- \\
0.400\end{array}$ \\
\hline Financial, insurance & 0.082 & 1.000 & 0.000 & 0.700 & $\begin{array}{l}- \\
0.167\end{array}$ & $\begin{array}{l}- \\
0.400\end{array}$ \\
\hline Real estate & 0.087 & 0.803 & 0.084 & 0.586 & $\begin{array}{l}- \\
0.400\end{array}$ & $\begin{array}{l}- \\
0.400\end{array}$ \\
\hline Prof, scient, techn & 0.087 & 1.000 & 0.080 & 0.798 & $\begin{array}{l}- \\
0.129\end{array}$ & $\begin{array}{l}- \\
0.400\end{array}$ \\
\hline Adminis, support & 0.087 & 1.000 & 0.214 & 0.363 & $\begin{array}{l}- \\
0.200\end{array}$ & $\begin{array}{l}- \\
0.200\end{array}$ \\
\hline Public administration & 0.085 & 1.000 & 0.000 & 0.416 & $\begin{array}{l}- \\
0.307\end{array}$ & $\begin{array}{l}- \\
0.200\end{array}$ \\
\hline Education & 0.100 & 1.000 & 0.018 & 0.900 & $\begin{array}{l}- \\
0.400\end{array}$ & $\begin{array}{l}- \\
0.400\end{array}$ \\
\hline Health, social work & 0.084 & 1.000 & 0.019 & 0.134 & $\begin{array}{l}- \\
0.200\end{array}$ & $\begin{array}{l}- \\
0.079\end{array}$ \\
\hline Arts, entertainment & 0.061 & 0.742 & 0.172 & 0.525 & $\begin{array}{l}- \\
0.200\end{array}$ & $\begin{array}{l}- \\
0.400\end{array}$ \\
\hline Other services & 0.061 & 0.604 & 0.327 & 0.143 & $\begin{array}{l}- \\
0.200\end{array}$ & $\begin{array}{l}- \\
0.200\end{array}$ \\
\hline
\end{tabular}

Notes: Col. (1): workers in parental leave from STATEC disaggregated by industry using IGSS data on workers aged 30 and less and workers with young children. Cols. (2): authors' computations. Col. (3): data on "chômage partiel" from IGSS. Col. (4): data on teleworking from the survey conducted by Chamber of Commerce in April. Col. (5): authors' computations based on the I/O matrix; Cols (6): authors' hypotheses based on the survey conducted by Chamber of Commerce in April.
Conditions) data allow to identify workers originating from Luxembourg, Germany, France and Belgium. The production side of the model relies on the assumption that the production technology is CobbDouglas in each sector, the parameters of which are calibrated to match the capital income shares and the levels of value added.

Placing ourselves back in April 2020, the problems were to nowcast the cost of the lockdown and forecast the consequences of a gradual deconfinement. We calibrated the economic block of the model to match the lockdown data available at the beginning of April. Our hypotheses are reported in Cols. 1-6 of Table 1 for all industries. ${ }^{12}$ They are based on the following sources (most of which are public or private institutions based in Luxembourg):

- The share of workers in parental leave after school closing $\left(\lambda_{\mathrm{it}}^{a}\right)$ is taken from STATEC (Institut national de la statistique et des études économiques), and split across industries and origin countries using the proportion of workers with children aged 6-15 from SILC. The government exceptionally offered a replacement rate of $80 \%$ for workers who were forced to leave their job due to school closing.

- The share of people in partial unemployment ("chômage partiel") due to lockdown measures $\left(u_{\mathrm{it}}^{a}\right)$ is obtained from ADEM (Agence pour le développement de l'emploi, the National Employment Agency), being aware that data on "chômage partiel" refer to applications and might overestimate the real extent of the employment effect. Unemployment and parental leave data are combined to proxy the postlockdown levels of employment by sector $\left(L_{i, t} \equiv \operatorname{Min}\left(L_{i, t}^{d}, L_{i, t}^{s}\right)\right)$.

- For the lockdown industries (i.e., manufacturing products; construction; wholesale and retail trade, repair services; transportation and storage services; accommodation and food services; real estate; arts, entertainment and recreation services; other services), we assume that the observed levels of employment correspond to the maximal labor supply $\left(\operatorname{Min}\left(L_{i, t}^{d}, L_{i, t}^{s}\right)=L_{i, t}^{s}\right)$ and calibrate $\phi_{i, t}$ as a residual from Eq. (10).

- In the other industries, we assume that $\operatorname{Min}\left(L_{i, t}^{d}, L_{i, t}^{s}\right)=L_{i, t}^{d}$. Observed employment levels are used to predict the value added and sales using Eq. (4). Assuming that non-lockdown industries are not supplyconstrained, final demand $\left(D_{i, t}+E_{i, t}\right)$ is made compatible with these output levels. More precisely, we use export forecasts of the ifo institute and calibrate $D_{i, t}$ as a residual from Eq. (5). It will appear later that these forecasts were too pessimistic, at least in the financial sector which represents a share of Luxembourg GDP that is close to $30 \%$.

- By contrast, lockdown industries are supply-constrained. Final demand cannot be observed. We assume a $20 \%$ decrease compared to normal times in industries producing essential goods, and a $40 \%$ decrease in industries producing non-essential goods, in line with the forecasts of the ifo institute.

- Finally, data on the share of workers in teleworking $\left(\tau_{i, t}^{a}\right)$ are taken from the survey of the Chamber of Commerce.

To put things in the context of October 2020, we update the hypotheses above using observed macroeconomic data for the first three quarters of 2020 from STATEC. The quarterly growth rates for 2020Q1, Q2 and Q3 are equal to $-1.4 \%,-7.2 \%$ and $+4.8 \%$, respectively. We recalibrated changes in final demand to match these numbers. In the absence of data by industry, we assumed proportional adjustments across sectors that are not subject to lockdown measures. We also updated data on teleworking and "chômage partiel" using data from STATEC and from ADEM. Parental leaves went back to their prelockdown levels after the reopening of schools. More details on the reparameterization will be provided in Section 3.2.

Parameterization of the epidemiological block. In our SIR

\footnotetext{
$\overline{12}$ A more detailed description is provided in Burzynski et al. (2020).
} 
compartmental model, transmission rates are calibrated to match data on the cumulative number of detected COVID-19 cases in the inactive population (students and retirees) and in the active population by sector. Daily data on COVID-19 cases by sector and by region of residence are available from the IGSS database from the beginning of March until October 19, 2021. ${ }^{13}$ We aggregate COVID-19 cases per week, creating a database of 34 weeks times 21 sectors of the society (714 observations) corresponding to $I_{i, t}^{a}$ in Eq. (6).

Over the same period, we also use national data on the shares of infected cases $\left(\bar{i}_{i, t}^{a}\right.$ for $a=(G, F, B)$ ) in the neighboring countries (used as proxies for Rhineland-Palatinate and Saarland for Germany, Grand Est for France, and Wallonia for Belgium). We calibrate time-varying transmission rates $\left(\beta_{i, t}^{a}\right.$ for $a=(G, F, B)$ ) in each of the three contiguous regions to match the evolution of the share of infected people, using a simplified and independent SIR model by region. We consider the trajectory of transmission rates in these regions as independent of the sanitary conditions in Luxembourg.

Transmission rates in Luxembourg are sector-specific. The philosophy of our parameterization is to rely on a limited number of parameters and fitting assumptions. Many epidemiological models rely on complex polynomial functions to fit many daily data points. Obviously, the higher the number of parameters, the better the fit. This does not mean that the predictive power of such complex models is satisfactory - at least over sufficiently long periods of time - and that these models can predict the effects of out-of-trend shocks such as a deconfinement or the implementation of a new public health policy measures. A more structural approach such as ours is worth investigating. Taking as given the parameters of the neighboring regions, we fit the 21 infection curves by estimating 3 parameters per sector (i.e., 21 times 3 parameters) and 2 parameters governing transmission rates outside the sector.

In Eq. (8), we compute proxies for $\left(\mu_{i, t}, \bar{\mu}_{i, t}\right)$ as explained at the end of this section, and combine them with data on employment and school attendance to proxy $e_{i, t}$. To compute $e_{i, t}$, we need to specify the share of weekly social interactions that occur in each sector of the society, $\varepsilon$. Fully employed workers spend about $55 \mathrm{~h}$ /week at the workplace and in transportation, and of a weekly total of $75 \mathrm{~h}$ of interactions with family members, friends and other contacts. Assuming professional interactions involve three times more contacts than private contacts, we obtain a fraction $\varepsilon=0.7$ on-the-job, and a fraction $1-\varepsilon=0.3$ in the place of residence. These fractions have little influence on the results as they determine the scale of the transmission parameters.

Within-sector transmission rates are thus influenced by three sectorspecific parameters, $\left(\bar{b}_{i}, \bar{\rho}_{i}, \chi_{i}\right)$. First, the scale parameter $\bar{b}_{i}$ determines the pre-lockdown transmission rates (before March 17th, 2020). Second, we allow $\bar{\rho}_{i}$ to be smaller than one in the weeks during which the sector is constrained by sanitary measures, and set it equal to unity otherwise. Third, we estimate $\chi_{i}$ using variations in transmission rates and presence rates in the sector. Similarly, transmission rates outside their main sector of activity (i.e., industry, school, retirees' sector) are influenced by two parameters, $\left(\bar{\beta}^{L}, \rho^{L}\right)$. The scale parameter $\bar{\beta}^{L}$ determines the prelockdown transmission rates outside the sector. We allow $\rho^{L}$ to be smaller than one in the weeks during which social and family activities are constrained, and set it equal to unity otherwise.

The calibration of the parameter set $\Gamma=\left(\bar{b}_{i}, \bar{\rho}_{i}, \chi_{i}, \bar{\beta}^{L}, \rho^{L}\right)$ relies on the Simulated Method of Moments, which identifies the vector of transmission rates to make simulated model moments $\left(\widehat{I}_{i, t}^{a}(\Gamma)\right)$ match data

\footnotetext{
${ }^{13}$ As our model does not include working-age individuals who are not registered to IGSS (i.e., inactive and dependent individuals), we re-scale the number of infected individuals by sector so that the total number of infected people living in Luxembourg exactly matches the total number of COVID-19 cases in the Luxembourg population. We apply the same rescaling factors to crossborder workers.
}

moments $\left(I_{i, t}^{a}\right)$ :

$\underset{\Gamma}{\operatorname{Min} \Lambda}=\sum_{t} \sum_{i} \sum_{a}\left(\widehat{I}_{i, t}^{a}(\Gamma)-I_{i, t}^{a}\right)^{2}$.

Fig. 1 compares our estimated infection curves (dashed black curves) with data on COVID-19 cases by sector (gray curves). Our fit is very good in most sectors of the society and excellent when focusing on the aggregate number of cases. As illustrated on the bottom-right graph, our model almost perfectly matches the evolution of the aggregate number of detected COVID-19 cases in the Luxembourgish workforce. In the prelockdown period, the correlation between $\bar{b}_{i}$ and indices of exposure to risk by industry - reflecting heterogeneity in workers' exposure to disease and physical distance at work - is around 0.6, suggesting that our method is meaningful. In the post-lockdown period, the correlation is small (around 0.1), suggesting that lockdown measures were effective in reducing physical distance and exposure to disease. ${ }^{14}$

Once transmission rates are known, we identify its components in line with Eq. (8). The third component, $\left[(1-\theta) \mu_{i, t}+\theta \bar{\mu}_{i, t}\right]$, depends on the share of asymptomatic subjects among contagious individuals and on the fractions of infected workers who are still active on the labor market. Regarding the share of asymptomatic $(\theta)$, the recent CON-VINCE Study (Snoeck et al., 2020) conducted on 1862 Luxembourgish individuals identifies 35 cases with antibodies. These include 11 individuals who self-report to have been tested positive in the past months. This means that $1.3 \%$ of individuals (24 out of 1862) were undetected. Applying this percentage to the whole population gives a stock of asymptomatic of around 8000, which is twice as large as the total stock of detected cases. Given the small number of people in the sample, the accuracy of these numbers is low. Our calibration assumes that $\theta=$ 0.5. ${ }^{15}$

The fractions of infected people who are still active within each sector of the society $\left(\mu_{i, t}, \bar{\mu}_{i, t}\right)$ depend on the efficiency and frequency of PCR testing. In the absence of testing, we assume that infected workers self-isolate when they show some symptoms. Asymptomatic people never self-isolate. Calculations presented in the Appendix of Burzynski et al. (2020) allow approximating the fraction of working days supplied by symptomatic and asymptomatic infected workers under several testing scenarios:

- In the absence of testing, we obtain $\mu_{i, t}=0.20$ and $\bar{\mu}_{i, t}=1.0$ for all $t$. - If a weekly test is performed, we have $\mu_{i, t}=0.15$ and $\bar{\mu}_{i, t}=0.25$ for all $t$.

- If a daily test is performed, we have $\mu_{i, t}^{v}=\bar{\mu}_{i, t}=0$ for all $t$.

- If a one-shot test is performed at time $T$, we have $\mu_{i, T}=\bar{\mu}_{i, t}=0$, and we get back to $\mu_{i, t}=0.20$ and $\bar{\mu}_{i, t}=1.0$ thereafter (i.e., for all $t>T$ ).

As massive testing was not implemented at the beginning of the lockdown, we can hypothesize that $\left[(1-\theta) \mu_{i, 0}+\theta \bar{\mu}_{i, 1}\right]=0.6$ at the beginning of the crisis. When simulating deconfinement plans, we consider several testing scenarios.

\section{Results}

The calibrated model is used to produce two sets of experiments. We

\footnotetext{
14 Results are presented in the Appendix of Burzynski et al. (2020).

15 Heneghan et al. (2020) cover 21 studies based on various contexts. The range of estimates of this proportion varies from $5 \%$ to $80 \%$. In the case of the Diamond Princess cruise in which all individuals were tested, about $18 \%$ were found to be asymptomatic. More recently, Fontanet et al. (2020) conduct a survey in a French high school involving pupils, teachers and non-teaching staff in the Oise region which was one of the first affected places of the epidemics in France. They find a rate of asymptomatic people of $17 \%$ only, but argue that this is likely to underestimate the rate in the general population.
} 


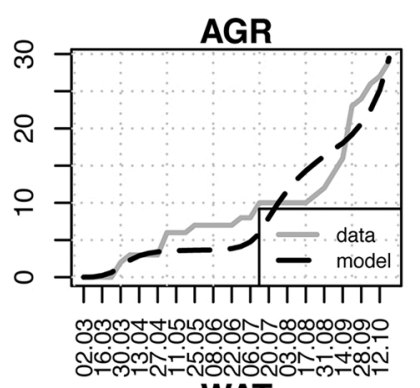

WAT

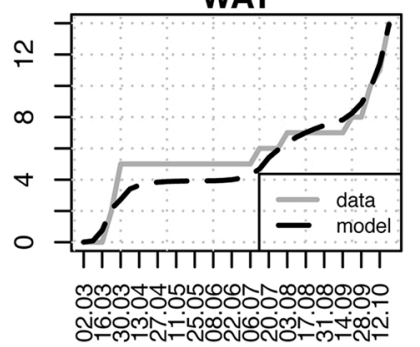

FOO
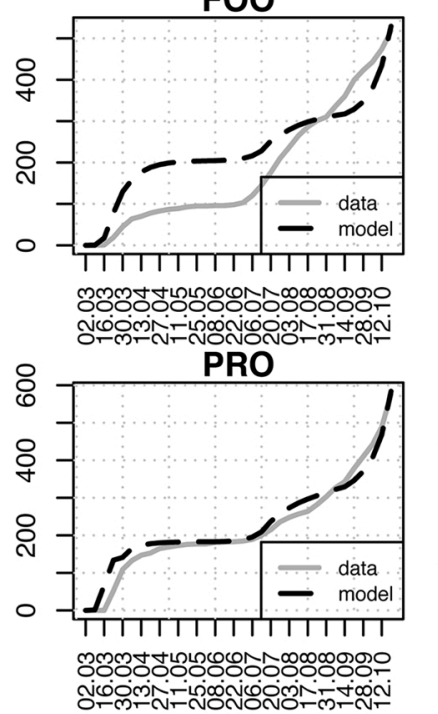

HEA
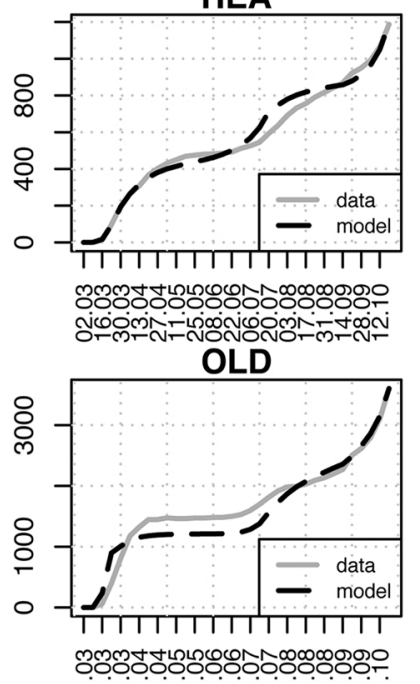
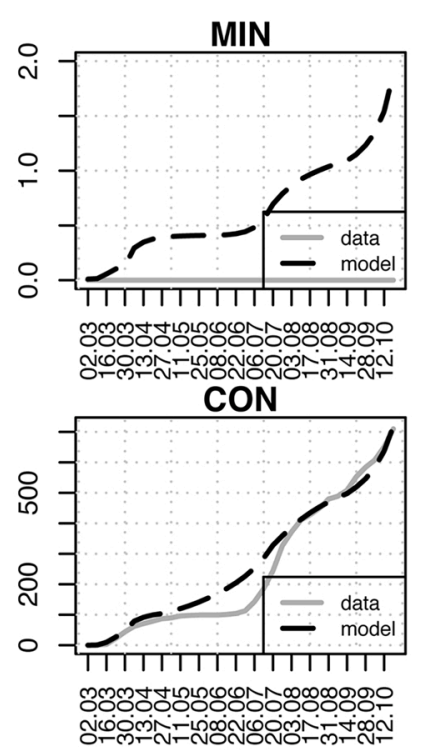

ICT

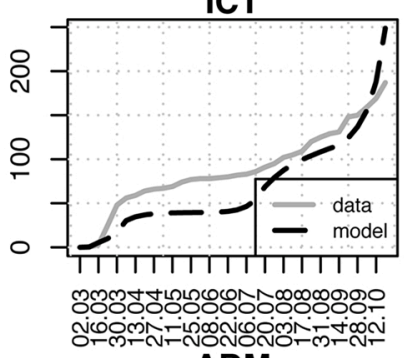

ADM

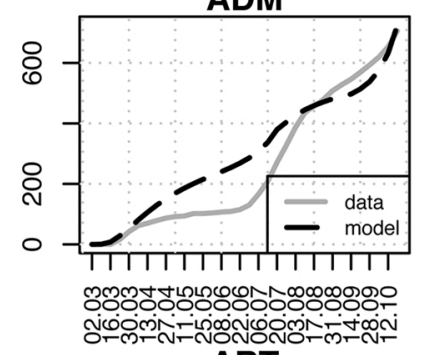

ART

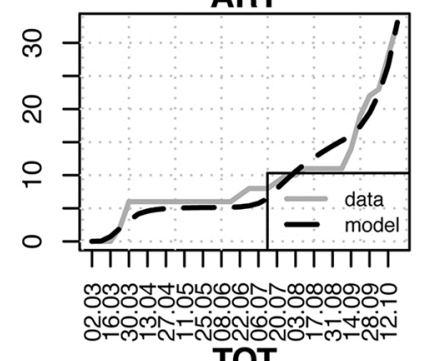

TOT

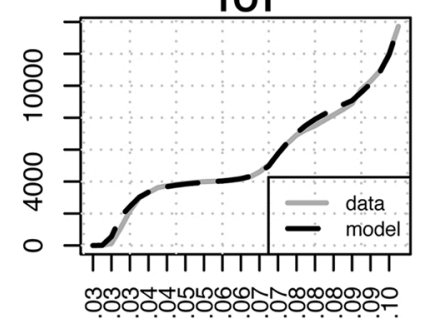

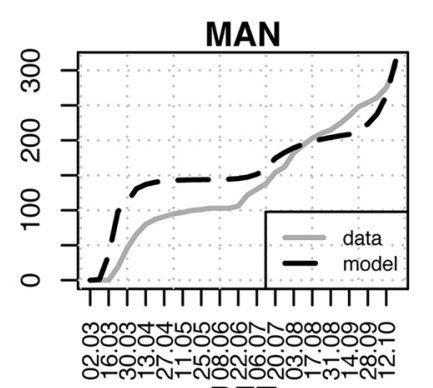

RET

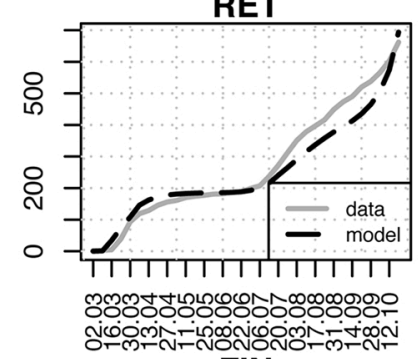

FIN

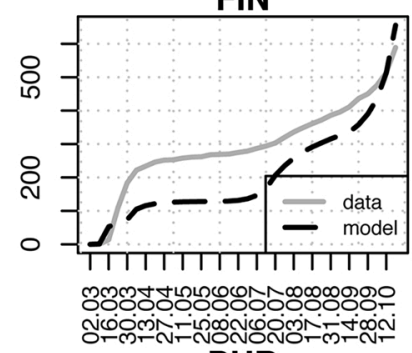

PUB

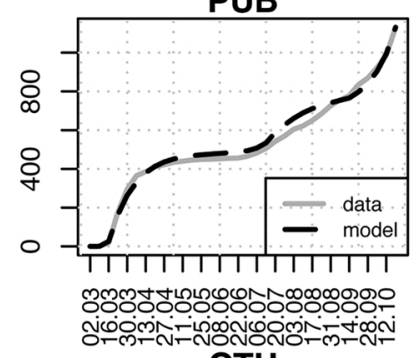

OTH

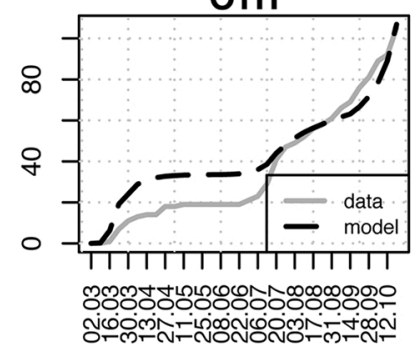

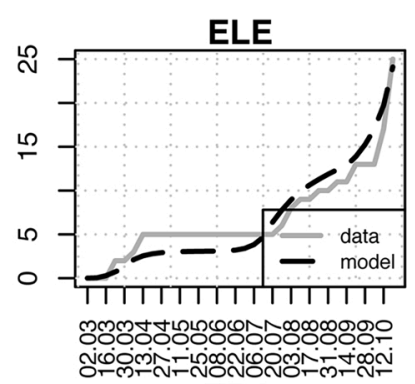

TRA

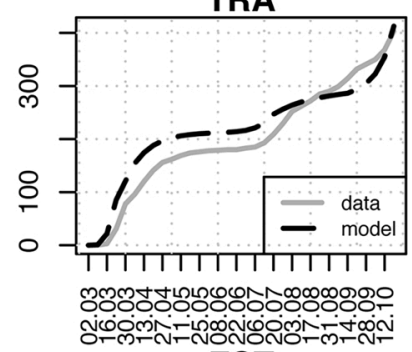

EST

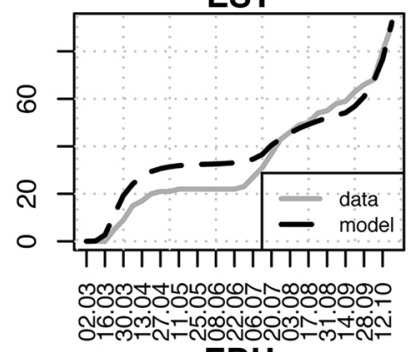

EDU

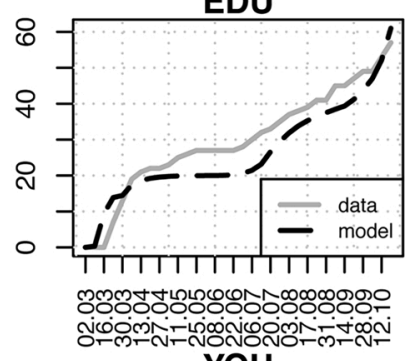

YOU

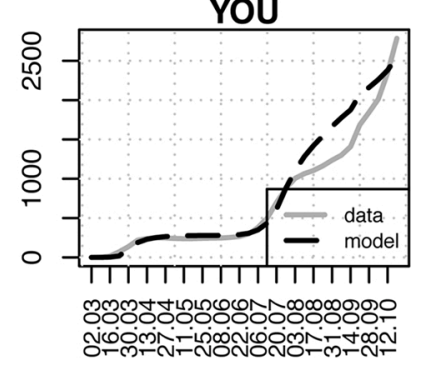

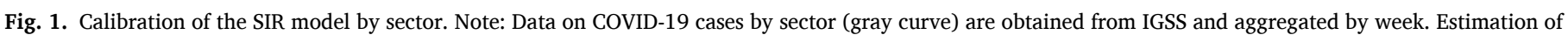
SIR model are represented by the dashed black curve. 
first use it to simulate the trajectory of public health and economic indicators during the first deconfinement period, from April to June 2020. This first part summarizes the results presented in the initial version of this paper (Burzynski et al., 2020). ${ }^{16}$ Next, we use our model to quantify the epidemiological and economic effects of the second wave of COVID-19 and related containment policies, extending the time horizon to cover the year 2021 .

\subsection{Back to May 2020: managing the first deconfinement}

Lockdown measures were implemented on 20 March 2020. Without taking stance on the potential trade-off concerning human lives vs. material goods and/or social losses, lockdown measures induce opposite economic and epidemiological consequences. On the one hand, they generate a decline in activity driven by a disciplined cut in lockdown industries, a decrease in final demand, and cascading effects in the other industries. Using industry-specific parameters from Table 1, our model predicts that each week of lockdown during the first wave translated into an output loss of about $28 \%$ compared to the pre-crisis level, as illustrated in Figure $2 \mathrm{~b}$. The most adversely affected industries were 'Construction' ( $-66 \%)$, 'Accommodation and Food' ( $-62 \%)$, Mining and Quarrying ( $-43 \%$ ), and 'Wholesale/retail trade and repair services' $(-42 \%)$. The least impacted industries are 'Health and social work' $(-3 \%)$ and 'Finance' $(-6 \%)$, 'Education' and 'Public administration' showed limited responses of around $10 \%$. On the other hand, the lockdown reversed the trend of rising infections.

As shown in Fig. 2a, the peak of the infection curves was observed during the first week of April with around 1850 detected COVID-19 cases (we exclude asymptomatic people who were not detected as positive). The number of infected people gets smaller than 50 by mid-June, implying a number of recovered people converging towards 4400 individuals (i.e., $0.7 \%$ of Luxembourg's population). The lockdown has drastically limited the propagation of the virus, which implies that there was still a majority of susceptible workers in the Luxembourg labor force after the first wave. Any economically meaningful strategy of deconfinement required that non-infected and non-immune workers were gradually brought back to work, which induced a risk of a relapse.

Deconfinement scenario. In Fig. 2, we simulate the economic and health implications of the deconfinement measures implemented between April and June 2020 in Luxembourg. The deconfinement policy was gradual:

- The first restarting stage started on April 20 and mainly involved the reopening of construction sites.

- Secondly, schools gradually reopened after May 4. Reopening started with graduating classes in the secondary education, practical exercise classes and internships at University and for the Advanced Technician Certificates. Secondary schools reopened on May 11. Primary schools and public childcare services reopened on May 25. This reduced the number of workers in parental leave.

- Other measures were implemented on May 11. These consisted of removing constraints in all other sectors of the economy, with the exceptions of HORESCA as well as Arts, Entertainment and Recreative Services.

- We also consider a resumption of social activities from the beginning of June. We allow transmission rates at the place of residence to partly return to their initial level once social life restarts. This might be due to restarting meals and parties with a limited number of friends and/or with family members, sport in small groups, more intensive use of public transportation, more contacts in shopping areas, mass departures during the holiday season or at weekends, etc.

\footnotetext{
16 The analysis of the first deconfinement period relies on a simplified model, which abstracts from the two inactive groups, namely students and retirees.
}

- To be consistent, we combine the deconfinement with the optimistic trade scenario involving a gradual recovery of exports from the beginning of June. We consider for the time being that teleworkers continue to work from home in the non-lockdown industries.

Epidemiomonic results. The public health effects of these measures are presented in Fig. 2a and b, in which we consider that testing policies are not implemented. As a benchmark, we consider a best-case scenario in which transmission rates within sectors and in the total population are kept at their post-lockdown levels. In the other scenarios, we assume that employment constraints are relaxed in all sectors (i.e., $\phi_{i, t}=1$ ), except HORESCA and Arts, Entertainment and Recreative Services. This increases the level of employment in all sectors, due to cascading economic effects. We analyze the effects of this deconfinement policy considering a set of sanitary scenarios. As a result from physical distancing, hygiene and prevention measures, transmission rates decreased drastically in Luxembourg and in the Greater Region after the lockdown. Part of the changes in transmission rates can be considered as permanent. In an optimistic scenario, depicted by the dashed black curve, we assume that (i) masks, distancing and hygiene measures are maintained and allow to keep transmission rates $\left(\bar{\rho}_{i}\right)$ at $50 \%$ of their prelockdown levels in all industries, (ii) post-lockdown teleworking practices remain in force in all sectors, and (iii) the resumption of social life has no effect on transmission rates outside the labor market and schools ( $\bar{\rho}^{L}$ is kept at the post-lockdown level). Due to intensive margin effects, this optimistic deconfinement scenario translates into a second (flatter) wave that reaches its peak in the course of 2021.

To illustrate the fragility of the health situation, we then consider that the resumption of social life influences transmission rates outside individuals' sector of activity, with $\bar{\rho}^{L}$ becoming equal to $50 \%$ of the prelockdown levels. We allow changes in $\bar{\rho}^{L}$ to materialize in Luxembourg only (dashed red curve) or in the regions of origin of cross-border workers only, i.e., in Wallonia in Belgium, Grand-Est in France, Saarland and Rhineland-Palatinate in Germany (dashed green curve). In both cases, the infection curves shifts upwards and the second wave is more severe. Finally, the blue curves show that bringing teleworkers back to their workplace (all workers in blue, or cross-border workers only in dashed blue) reinforces the intensive-margin effects and generates a rapid and drastic increase in the infection curve.

The economic effects are depicted in Fig. 2b. In the best-case scenario, weekly GDP slowly goes back to its pre-crisis level before the end of the year. Remember that this scenario assumes a gradual recovery of final demand after June 2020. Considering the worst-case epidemiological scenario (with changes in $\bar{\rho}_{i}$ and $\bar{\rho}^{L}$ ) has limited economic effects as the number of infected peaks at around 15,000 persons, including 10,000 workers ( $2 \%$ of the workforce) who can be partially replaced by those in partial unemployment. Hence, the effect of changes in the flow of new infections on the economy are rather small, contrary to the huge effects induced by generalized or partial lockdown measures. Overall, the annual GDP decreases by $8 \%$ compared to a no-crisis scenario. By contrast, assuming that changes in exports are permanent would lead to a long-lasting drop in GDP and an annual input loss of $15 \%$. Hence, in an open-economy context such as in Luxembourg, economic prospects for 2020 were highly sensitive to international economic conditions. For illustrative purpose, we also simulated a scenario in which all crossborder workers and teleworkers are unemployed, the loss of GDP would have exceeded $30 \%$. The role of teleworking has been instrumental to limiting the economic output loss and the propagation of the virus.

Testing policies. The results above indicate that the deconfinement policy implemented between April and June 2020 was likely to generate a second wave if it was not accompanied by appropriate testing and tracing measures. In Fig. 2c, we start from a scenario combining intensive margin effects with changes in $\bar{\rho}_{i}$ and $\bar{\rho}^{L}$ (a mix of dashed black and dashed red curves in Fig. 2a). The continuous black curve clearly 
(a) Fragility of the sanitary situation

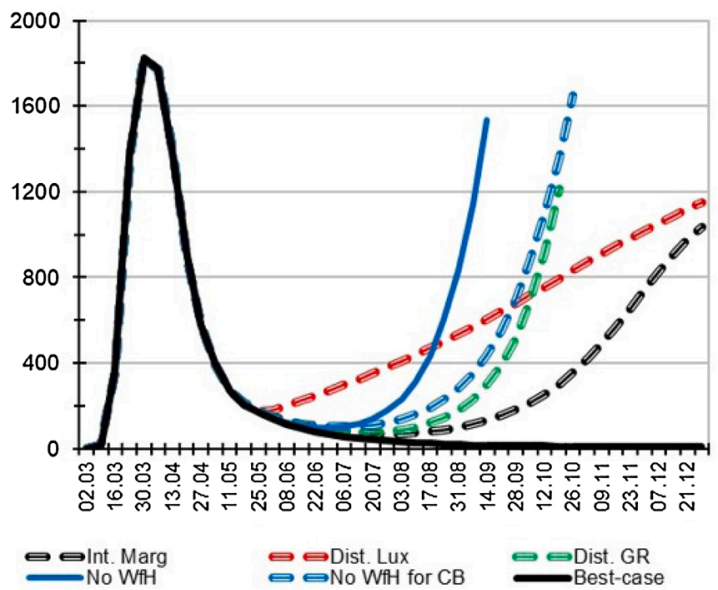

(b) Economic scenarios for 2020

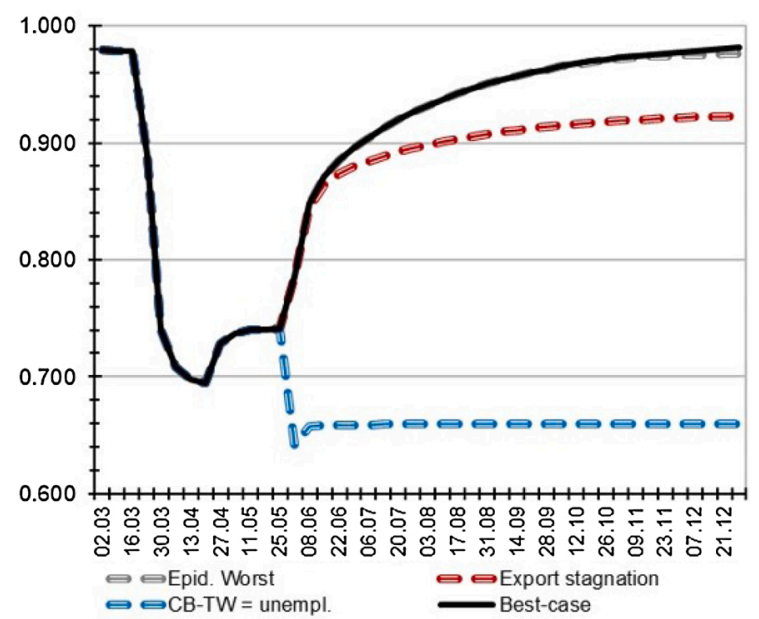

(c) Effectiveness of testing policies

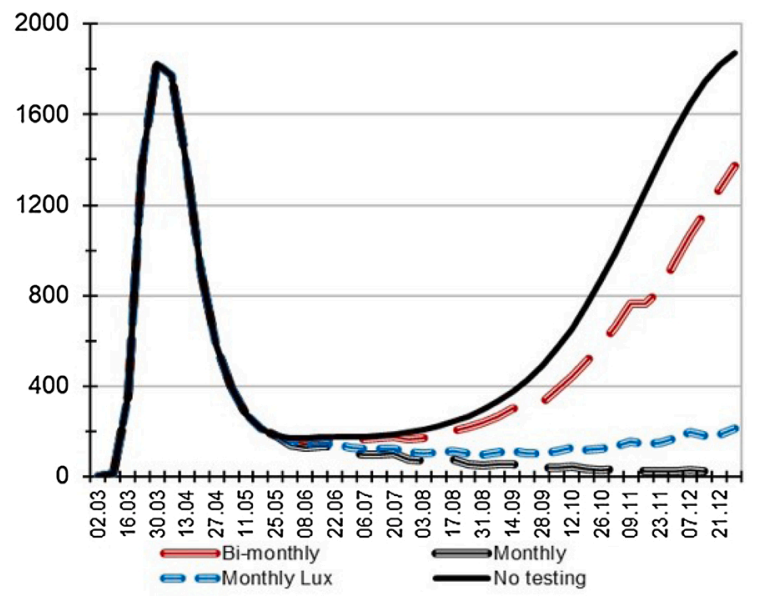

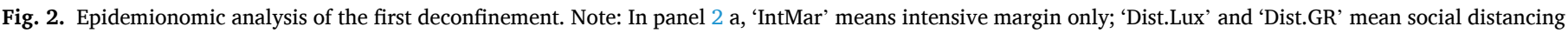

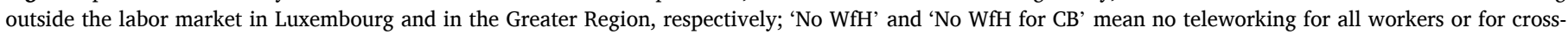

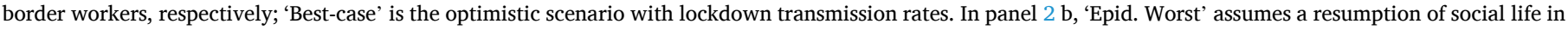

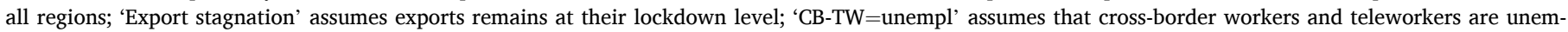

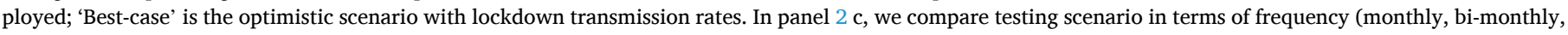

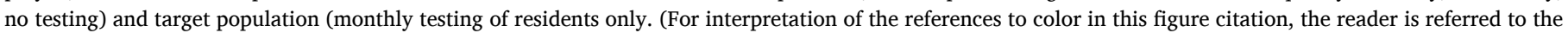
web version of this article.)

indicates that a second wave occurs in the absence of testing. Starting from the same transmission rates, we simulate the effect of bi-monthly and monthly tests, as well as monthly tests for domestic workers only (i.e., excluding cross-border workers).

We find that testing all workers and residents once per month (dashed black) is sufficient to avoid the second wave. By contrast, testing domestic workers only (blue dashed curve) generates a slow and gradual relapse of the pandemic, and testing all workers every two months generates a quick and drastic rebound. Obviously, stricter testing policies are needed if one considers a more pessimistic scenario where teleworkers are brought back to work or if transmission rates cannot be kept below $50 \%$ of their pre-lockdown levels. Although April-May-June 2020 was a good time for lifting containment measures, our model was helpful to highlight the fragility of the sanitary situation. In particular, epidemiological predictions were highly sensitive to the evolution of teleworking practices, transmission rates outside the labor market, and testing policies. Three precautionary measures were drawn from our initial analysis (Burzynski et al., 2020):

17 Maintaining teleworking practices is vital, at least in industries where working-from-home practices are feasible. ${ }^{17}$ All of our simulation results indicated that a cessation of teleworking practices would induce large epidemiological damages, even if drastic mitigation policies were implemented.

18 Maintaining hygiene measures and high levels of physical distancing in social life has an important impact on the number of COVID-19 cases. Our results also indicated that the evolution of the number of COVID-19 cases is highly sensitive to transmission rates outside the labor market.

\footnotetext{
17 Dingel and Neiman (2020) show that only $37 \%$ of jobs in the U.S. can be performed entirely remotely. There is a risk that teleworking practices exacerbate pre-existing inequalities in the labour market, especially if they are not adequately regulated (Bonacini et al., 2021a,b).
} 
19 Monthly PCR testing of domestic and cross-border workers were necessary (but perhaps not sufficient) to prevent a rebound in the infection curve.

20 Combining testing with contact tracing would reduce transmission rates further. Ferretti et al. (2020) show that tracing pre/a-symptomatic people with a phone app and quarantining contacts of new detected cases would reduce the transmission rate by up to $50 \%$.

21 Preventing HORESCA activities to exceed half of their full capacity was also recommended.

Ex-post evaluation. Four months after our studies, available statistics allowed to assess the relevance of our nowcasts, forecasts and recommendations. A rebound in the infection curve appeared in late July, followed by a drastic second wave which started to materialize in September. In line with our model predictions, this second wave can be essentially explained by a decrease in the share of teleworkers and, more importantly, by the changes in transmission rates outside the labor market (in schools and in social life) and by the coverage of the testing policy. Although the government invited its residents and cross-border workers to be tested on a monthly basis, between 25th May and 15th September the participation rate has been around 49\% among the population resident in Luxembourg and $22.5 \%$ among the cross-border workers (Wilmes et al., 2021), which is almost equivalent to testing everyone every three months only. Hence, the Luxembourg testing agency operated way under its capacity levels, and was able to deliver testing results within less than a day only. The model predicted that the second wave was inevitable under these circumstances.

Economically speaking, the model correctly predicted that the direct impact of changes in the infection curve on the economy proved to be relatively small. This is because the stock of infected people never exceeded $2 \%$ of the population, and workers in sick leave could easily be replaced by workers in partial unemployment. By contrast, containment measures induced large economic costs. Data reveals that GDP decreased drastically during the lockdown months, although our economic forecasts proved to be too pessimistic. The economy has been more resilient than expected, which is mostly due to the fact that the domestic and international demand for financial services did not decrease as strongly as assumed in Table 1 . Overall, the economic loss amounted to $1.4 \%$ and $7.2 \%$ in the first and second quarters of 2020 , while our model predicted twice these amounts. The model assumptions were thus revised in October 2020 to predict the epidemiological and economic consequences of the second wave, as explained in the next section.

\subsection{Back to October 2020: managing the second wave}

The outlook for the global economy was highly uncertain after the summer 2020. In October 2020, we relied on scenarios developed by Oxford-Economics (2020) to delineate best-case and worst-case macroeconomic scenarios for Luxembourg's GDP over the quarters of 2020 and $2021 .{ }^{18}$ We adjusted our sanitary and final demand hypotheses to be compatible with these extreme scenarios, defined an intermediate and more relevant scenario relying on the moderately coercive measures implemented in the country, and predicted its epidemiological and economic effects for 2020 and 2021.

Second-wave scenarios. The best-case scenario (labeled as NoSW) assumes the absence of a second wave and a quick recovery of the international environment. It predicts that scientific advances will be such that restrictions can be completely lifted from 2020Q4. The effects of fear and uncertainty on final demand gradually disappear during 2020Q4 and 2021Q1. Using observed macroeconomic data for the first

\footnotetext{
18 The latter were elaborated with the help of STATEC, building on their flagship macroeconomic model Modux.
}

three quarters of 2020, STATEC estimates that this NoSW scenario translates into annual GDP growth rates of $-3.5 \%$ in 2020 and $+4.0 \%$ in 2021, which basically means a fast recovery towards the no-COVID trend. The underlying epidemiological trajectory assumes that virus transmission rates decrease monotonically towards zero between September 2020 and May 2021, and that medical advances (including a large-scale vaccination campaign) make it possible for social distancing to fully relax without implying a rebound in the infection curve.

By contrast, the worst-case scenario (labeled as SWLO) predicts a second wave requiring generalized lockdowns throughout Europe. In the case of Luxembourg, STATEC assumes a new confinement of longer duration (covering 6 months during 2020Q4 to 2021Q1) in the same industries as in March-April (i.e., construction, sales in non-essential businesses, services to households, food and accommodation) as well as in leisure, family and social life. This will be accompanied by a longlasting decrease in final demand due to lockdowns abroad and to a degradation of the confidence of local and foreign actors. STATEC estimates that this 'SWLO' translates into annual GDP growth rates of $4.5 \%$ in 2020 and $-0.5 \%$ in 2021, implying two years of negative real growth. The underlying epidemionomic trajectory suggests that GDP will be $15-17 \%$ below the 'No-COVID' hypothetical trend during the lockdown weeks and will slowly recover afterwards.

The reality is somewhere in the middle. After a dip in new cases in July and August, Luxembourg reported a higher number of cases than during the first peak. Hence, the second wave materialized and the question was: how bad will it be? Luxembourg avoided to strongly reconfine its economy in late October 2020. Besides testing, tracing and quarantining tools, the government decided to prohibit movements of people between 11PM and 6AM (i.e., a curfew), to reinforce social distancing measures in restaurants, bars and cafés, to limit private gatherings and presence in shops, to promote medical teleconsultation, to forbid sports activities involving more than four people, etc. The effectiveness of these sanitary measures and their economic implications are highly uncertain as they strongly depend on the degree of adhesion of the population as well as on external factors such as the evolution of preventive measures and epidemionomic conditions in the neighboring regions. In addition, after November 26, the government reimplemented a partial lockdown, which consisted of limiting family contacts and closing cafés and restaurants, cinemas, theaters, swimming pools and sport centers.

We relied on an optimistic parametric interpretation of these sanitary measures, that we refer to as the SWNL scenario (for 'second wave with no generalized lockdown'). More precisely, compared to early October and starting in November 2020, we assume a 50\% decrease in contamination rates outside the labor market in the neighboring regions, and an increase in teleworking (up to $50 \%$ of the April level). We also assume a trajectory of final demand that is less optimistic than under NoSW ( $-20 \%$ in 2020Q4 and 2021Q1, followed by a gradual recovery) due to consumers' fears and uncertainty. We also considered a new lockdown in HORESCA and in the "Arts, Entertainment and Recreative Services" from November 26 to the end of $2020 .{ }^{19}$

A spectrum of epidemionomic prospects. Fig. 3 depicts the aggregate results of our model, and Table 2 summarizes estimates of quarterly growth rates for the years 2020 and 2021. Under the NoSW, the spread of the virus remains rampant until June 2021 with low intensity from January. Under the SWLO scenario, a new generalized lockdown starting in September 2020 would have prevented the infection curve to skyrocket.

The most likely scenario (SWNL) generates intermediate results. Our parametric interpretation of sanitary measures has been chosen to generate a decrease in the infection curve that is comparable to that of

\footnotetext{
19 Note that the average occupancy rate in hotels was already low, in the range of 15 to $25 \%$ of their pre-lockdown levels, according to recent newspaper article.
} 

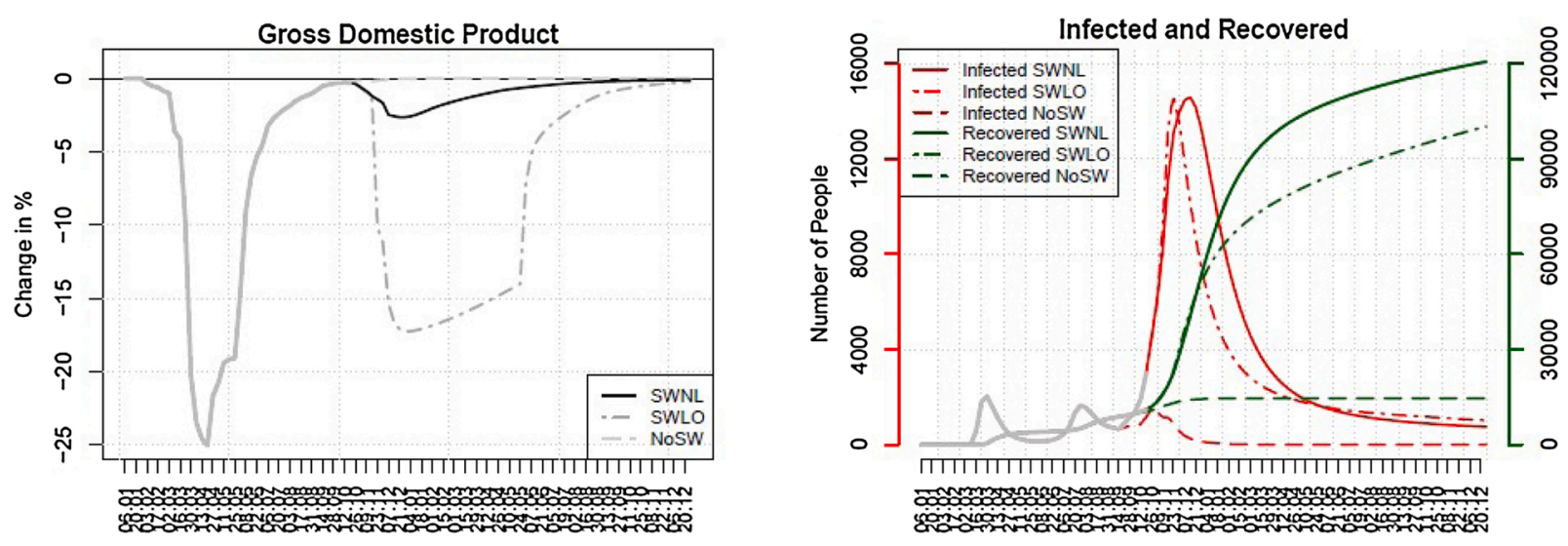

Fig. 3. Weekly path of epidemionomic outcomes under three scenarios. Note: The left panel reports the percentage of deviation in weekly GDP from the hypothetical "No-COVID" situation. The right panel reports the number of detected COVID-19 active cases (left scale) and the total number of recovered (right scale). NosW means no second wave; SWLO means no second wave due to a new generalized lockdown; SWNL means a second wave managed with moderately coercive measures.

Table 2

Trajectory of Luxembourg GDP under three scenarios, 2020-2021 by quarter.

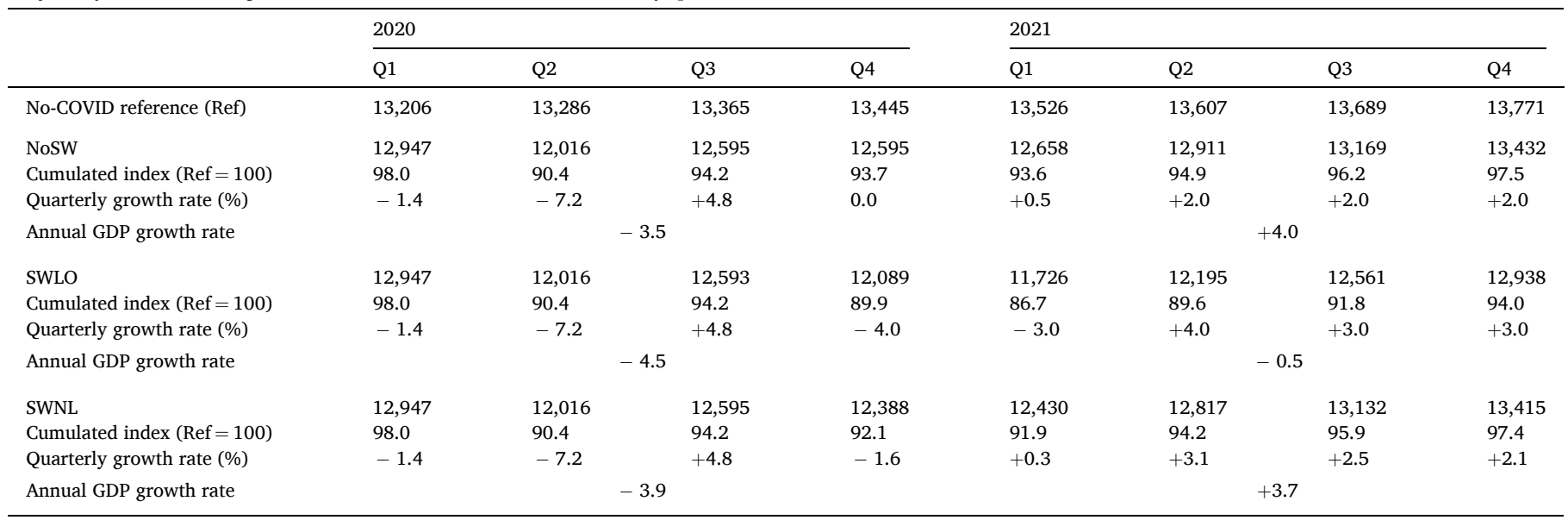

Note: The No-COVID reference scenario assume a 1.5\% growth rate per quarter. NoSW stands for absence of second wave. SWLO stands for second wave requiring a generalized lockdown. SWNL stands for second wave requiring moderately coercive measures only. Numbers for 2020Q1 and 2020Q2 are observations. Source: STATEC (2020). Note de Conjoncture of December 2020.

the lockdown scenario, which has been confirmed by the observed trajectory of the infection curve. The model predicts that the number of symptomatic active COVID cases peaks at 14,500 by mid-December 2020 (one month later compared with SWLO) and then fall until May 2021. By the end of 2021, the cumulative share of people who have ever been infected will be around $25 \%$ (i.e., 120,000 individuals). These results are moderately influenced by the sanitary conditions in the neighboring regions, except under extreme scenarios. ${ }^{20}$ The major difference with SWLO relates to the macroeconomic implications of the

\footnotetext{
$\overline{{ }^{20}}$ In unreported results, we simulated the trajectory of the infection curve under two scenarios in all contiguous regions (transmission rates equal to zero, or five times larger than those resulting from the SIR models for Belgium, France and Germany). Similar findings are found in the pessimistic scenario, with a peak at 15,000 COVID cases by mid-December. By contrast, we obtain a peak of 7,500 COVID cases under the (over-)optimistic scenario with zero transmission rates.
}

containment measures. We estimate that this SWNL scenario translates into annual growth rates of $-3.9 \%$ in 2020 and $+3.7 \%$ in 2021 , which is quite close to the NoSW scenario ( $-3.5 \%$ and $+4.0 \%$, respectively). ${ }^{21}$ Hence, managing the second wave with moderately coercive measures has limited the cost of the second wave to 0.3 and 0.4 percentage point of GDP in 2020 and 2021, respectively.

Sensitivity to hypotheses. There was considerable uncertainty on whether moderately coercive sanitary measures will prove strong enough to contain the second wave and on the concomitant evolution of the international environment. The predictions of the SWNL strongly depend on our parametric interpretation of existing measures. To quantify that uncertainty and to identify the key mechanisms at play, we started from the SWNL and considered 8 variants (one variant at a time) implying (i) more or less teleworking ( $100 \%$ vs. $0 \%$ of the sectoral share of March-April), (ii) higher or lower adhesion to distancing measures in

\footnotetext{
${ }^{21}$ Simulations in line with the robustness checks below suggest that about 3/4 of the growth differential with NoSW in 2020Q4 is due to epidemiological effects: the labor force decreases by about 30,000 persons in December (14,500 infected and approximately the same number of quarantined people). By contrast, the stock of active cases will be much smaller in 2021 and $4 / 5$ of the growth differential in $2021 \mathrm{Q} 1$ is due to the deterioration of final demand.
} 

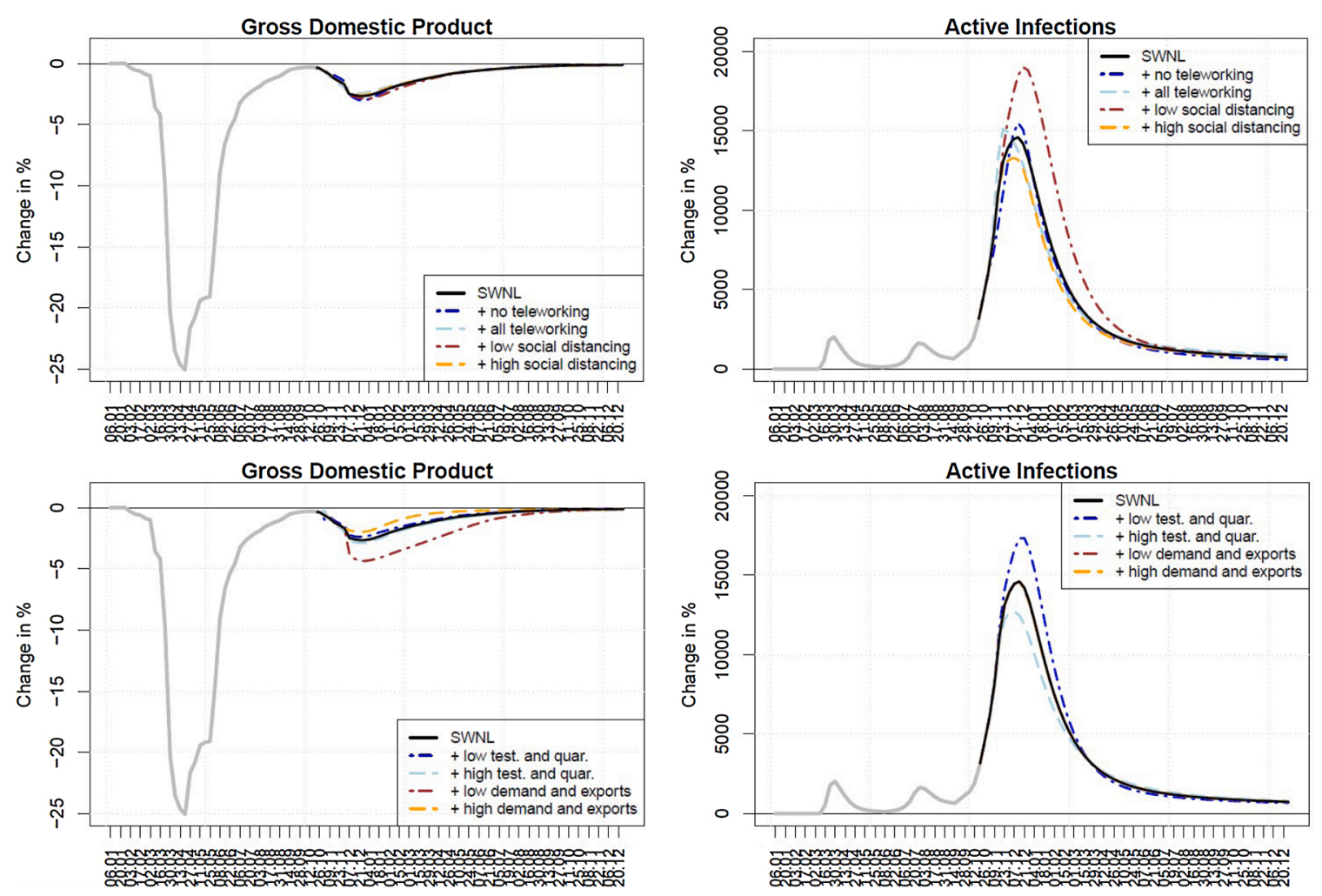

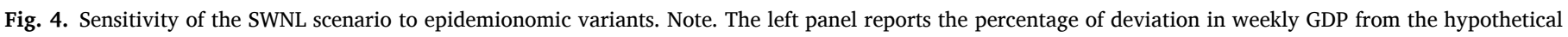
"No-COVID" situation. The right panel reports the number of detected COVID-19 active cases.

leisure, social and family life (contamination rates outside the labor market equal to $25 \%$ or $75 \%$ of those observed in early October), (iii) more or less testing/tracing ( $50 \%$ of participation in large-scale testing and 6 quarantined people per case vs. total absence of testing/tracing), (iv) more optimistic or pessimistic trajectory for exports (no shock vs. $40 \%$ in 2020Q4 and 2021Q1). These variants are considered as independent of each other, which means that we disregard the fact that variations in the infection curve can induce pressures on ICU admissions, panic or protest movements, which could translate into final demand responses. Fig. 4 illustrates the epidemionomic consequences of these alternative scenarios.

We first focus on adhesion to public health measures. Changes in teleworking practices have small effects on the infection curve. Within the context of our model, this is explained by the fact that highest transmission rates during the second wave were observed outside the labor market. Changes in social distancing have bigger effects, increasing the number of cases by 4,500 at the peak (low distancing) or decreasing it by 1,000 (high distancing). ${ }^{22}$ Changes in testing/tracing practices induce moderate epidemiological effects, increasing the number of cases by 2,500 at the peak (absence of large-scale testing and tracing) or decreasing by 1,500 (higher adhesion). These sanitary variants induce negligible effects on the economy (contrary to the deep-set trend in COVID cases), while annual GDP growth rates are sensitive to the evolution of the international environment. Turning our attention to export shocks, we find opposing results. The epidemiological consequences of output and employment shocks are negligible, which again results from the fact that transmission rates on the job were relatively well contained. By contrast, the economic trajectory for 2021 is sensitive to exports. For 2020, the effect is smaller as GDP levels for Q1 to Q3 are

\footnotetext{
${ }^{22}$ The low-distancing variant roughly translates into 140 admissions in intensive care units by the very end of the year, leading to a quasi-saturation of the ICU system.
}

already given. In particular, the low-export variant translates into an annual growth rate of $-3.9 \%$ in 2020 and $2.9 \%$ in 2021 (against $3.8 \%$ and $+3.6 \%$ under SWNL). From an epidemiological point of view, a lockdown-type policy during the second wave would have generated much more foreseeable epidemiological effects, in particular a considerably lower number of infections likely leading to fewer deaths, at the cost of a much bigger recession. It is thus crucial to underline once more that some measures aimed at containing the spread of the infection come with a combination of economic and epidemiological consequences, thus carefully considering the trade-off between these aspects is crucial in deciding about intervention strategies. It remains an open, somewhat subjective question how to weight these different aspects in an optimal way.

\section{Conclusion}

Our model jointly endogenizes the health and economic responses to the COVID-19 crisis and the related containment and public health policy measures implemented in Luxembourg and in its neighboring regions. It allows us to quantify the economic and public health effects of the first and second waves of COVID-19 under various economic, epidemiological and public health scenarios. We focus here on two key moments in time. The first one is the deconfinement period following the first lockdown (May-June 2020). Our set of nowcasts and policy experiments conducted in May 2000 predicted that the restarting of lockdown industries per se was unlikely to induce a relapse of the pandemic if teleworking practices could be maintained. Nevertheless, we predicted that the resumption of social life and, to a lesser extent, the cessation of teleworking practices were likely to generate a rebound in the infection curve. We thus recommended to maintain teleworking practices and high levels of physical distancing in social life, as well as promoting monthly testing and quarantining measures. Available statistics revealed that we overestimated the economic costs of the first wave; this is because the financial sector has been much more resilient 
than initially assumed. However, the second wave materialized after the Summer 2020. In line with our predictions, this is explained by higher transmission rates outside the labor market, low participation in testing and a decrease in teleworking.

Five months later, history was repeating itself. As the COVID-19 second wave was hitting much of Europe, some countries entered a new (total or partial) lockdown allowing people to leave their home only to go to work (when teleworking was not feasible) or to buy essential goods and seek medical help, banning or limiting social gatherings, prescribing curfews, shutting non-essential activities, etc. Luxembourg followed suit by taking new measures but avoided to re-confine part of its economy. Besides testing, tracing and quarantining tools, the government decided to prohibit movements of people between 11PM and $6 \mathrm{AM}$, to reinforce social distancing measures in public transport, to limit private gatherings and presence in shops, to promote medical teleconsultations, to forbid sport activities involving more than four people, and to close restaurants, bars and cafés. We re-parameterized our model to assess the effectiveness of these sanitary measures and the macroeconomic cost of the second wave. We estimate that the management of the second wave translates into moderate GDP losses in the years 2020 and 2021. If Luxembourg can escape a massive third and/or fourth wave, real GDP growth should almost get back to its long-term level in 2021.

\section{Conflict of interest}

None declared.

\section{Acknowledgments}

We thank the editor and three anonymous referees for their helpful comments and suggestions. We acknowledge financial support from the Luxembourg National Research Fund (FNR) under the COVID-19 Fast Track-2 programme (MODVid project - ref. 14854549). This paper was prepared to assist the Task Force for the Coordination of the Public Research Sector in the Context of the COVID-19 Pandemic (Work Package 7 on the socio-economic impact of the crisis, led by Aline Muller). Atte Aalto is supported by FNR (Project code: 13684479). Jorge Goncalves is partly supported by the 111 Project on Computational Intelligence and Intelligent Control (ref B18024). Françoise Kemp is supported by the FNR PRIDE17/12244779/PARK-QC. Stefano Magni and Daniele Proverbio are supported by the FNR PRIDE DTU CriTiCS (ref 10907093). The findings in this paper do not necessarily represent the views of the FNR and the Luxembourg COVID-19 Task Force. Any errors or omissions are the authors' responsibility.

\section{References}

Alvarez, F., Argente, D., Lippi, F., 2020. A Simple Planning Problem for Covid-19 Lockdown. NBER Working Papers, p. 26981.

Atkeson, A., 2020. What Will Be The Economic Impact of Covid-19 in the US? Rough Estimates of Disease Scenarios. Staff Report, Fed Reserve Bank of Minneapolis, p. 595.

Baldwin, R., Weder di Mauro, B., 2020. Economics in the Time of Covid-19. VoxEU.org Book, CEPR.

Barbieri, T., Basso, G., Scicchitano, S., 2020. Italian Workers at Risk During the Covid-19 Epidemic. INAPP WP, p. 46.

Barro, R., Ursua, J., Weng, J., 2020. Coronavirus Meets the Great Influenza Pandemic. VoxEU, March.

Barrot, J., Grassi, B., Sauvagnat, J., 2020. Sectoral Effects of Social Distancing, Vol. 3. Covid Economics Vetted and Real-Time Papers, pp. 85-102.

Berger, D., Herkenhoff, K., Mongey, S., 2020. An SEIR Infectious Disease Model With Testing and Conditional Quarantine. NBER Working Papers, p. 26901.

Bonacini, L., Gallo, G., Patriarca, F., 2021a. Working from home and income inequality: risks of a 'new normal' with covid-19. Identifying Policy Challenges of COVID-19 in
Hardly Reliable Data and Judging the Success of Lockdown Measures, vol. 34, pp. 275-301.

Bonacini, L., Gallo, G., Scicchitano, S., 2021b. Working from home and income inequality: risks of a 'new normal' with covid-19. J. Popul. Econ. 34, 303-360.

Brodeur, A., Grigoryeva, I., Kattan, L., 2020. Stay-At-Home Orders, Social Distancing and Trust. IZA Discussion Paper, p. 13243.

Burzynski, M., Machado, J., Aalto, A., Beine, M., Goncalves, J., Haas, T., Kemp, F., Magni, S., Mombaerts, L., Picard, P., Proverbio, D., Skupin, A., Docquier, F., 2020. Covid-19 Crisis Management in Luxembourg: Insights From An Epidemionomic Approach. LISER Working Paper series, pp. 2020-2108.

Correia, S., Luck, S., Verner, E., 2020. Pandemics Depress the Economy, Public Health Interventions Do Not: Evidence from the 1918 Flu. Manuscript available online at htt ps://ssrn.com/abstract $=3561560$.

Depalo, D., 2021. True covid-19 mortality rates from administrative data. J. Popul. Econ. $34,253-274$.

Dingel, J., Neiman, B., 2020. How many jobs can be done at home? J. Public Econ. 189 (C.

Docquier, F., Golenvaux, N., Schaus, P., Stips, F., 2021. Cross-border mobility responses to covid-19 in Europe: new evidence from facebook data. Manuscript. https://doi. org/10.21203/rs.3.rs-479253/v1.

Eichenbaum, M., Rebelo, S., Trabandt, M., 2020. The Macroeconomics of Epidemics. NBER Working Papers, p. 26882.

Fadinger, H., Schymik, J., 2020. The Costs and Benefits of Home Office During the Covid19 Pandemic: Evidence From Infections and An Input-Output Model for Germany, Vol. 9. Covid Economics Vetted and Real-Time Papers, pp. 107-134.

Favero, C., Ichino, A., Rustichini, A., 2020. Quantifying SARS-COV-2 Transmission Suggests Epidemic Control With Digital Contact Tracing. CEPR Discussion Paper, p. 14664.

Ferretti, F., Wymant, C., Kendall, M., Zhao, L., Nurtay, A., Abeler-Dorner, L., Parker, M., Bonsall, D., Fraser, C., 2020. Quantifying sars-cov-2 transmission suggests epidemic control with digital contact tracing. Science 368 (6491).

Fontanet, A., Tondeur, L., Madec, Y., Grant, R., Besombes, C., Jolly, N., FernandesPellerin, S., Ungeheuer, M.-N., Cailleau, I., Kuhmel, L., Tenman, S., Huon, C., Chen, K., Crescenzo, B., Munier, S., Demeret, C., Grzelak, L., Staropoli, I., Bruel, T., Gallian, P., Cauchemez, S., van der Werf, S., Schwartz, O., Eloit, M., Hoen, B., 2020. Cluster of covid-19 in northern France: a retrospective closed cohort study. medRxiv.

Gourinchas, P., 2020. Flattening the Pandemic and Recession Curves. VoxEU. March.

Greenstone, M., Nigam, V., 2020. Does Social Distancing Matter?, Vol. 7. Covid Economics Vetted and Real-Time Papers, pp. 1-22.

Heneghan, C., Brassey, J., Jefferson, T., 2020. Covid-19: What Proportion Are Asymptomatic? Online publication available at: https://www.cebm.net/cov id-19/covid-19-what-proportion-are-asymptomatic/.

Jones, C., Philippon, T., V, V., 2020. Optimal Mitigation Policies in a Pandemic: Social Distancing and Working From Home. NBER Working Paper, p. 26984.

Koren, M., Peto, R., 2020. Business Disruptions From Social Distancing Matter, Vol. 2. Covid Economics Vetted and Real-Time Papers, pp. 13-31.

Liu, Y., Gayle, A.A., Wilder-Smith, A., Rocklöv, J., 2020. The reproductive number of COVID-19 is higher compared to SARS coronavirus. J. Travel Med.

Milani, F., 2021. Covid-19 outbreak, social response, and early economic effects: a global var analysis of cross-country interdependencies. J. Popul. Econ. 34, 223-252.

Mongey, S., Pilossoph, L., Weinberg, A., 2020. Which Workers Bear the Burden of Social Distancing Policies? NBER Working Paper, p. 27085.

O'Donoghue, C., Sologon, D., Kyzyma, I., McHale, J., 2021. Modelling the distributional impact of the covid-19 crisis. Fiscal Stud. 41 (2), 321-336.

OECD, 2020. Evaluating the Initial Impact of Covid-19 Containment Measures on Economic Activity. Note is Produced by the OECD Economics Department, March.

Oxford-Economics, 2020. Global Scenarios Service: Q2 2020 - After the Pandemic. Oxford Economics Ltd, London.

Palomino, J., Rodriguez, J., Sebastian, R., 2020. Wage inequality and poverty effects of lockdown and social distancing in Europe. Eur. Econ. Rev. 129.

Papanikolaou, D., Schmidt, L., 2020a. Telework and Time Use in the United States. GLO Discussion Paper, p. 546.

Papanikolaou, D., Schmidt, L., 2020b. Working Remotely and the Supply-Side Impact of Covid-19. NBER Working Paper, p. 27330.

Qiu, Y., Chen, X., W, S., 2020. Impacts of social and economic factors on the transmission of coronavirus disease 2019 (covid-19) in China. J. Popul. Econ. 1127-1172.

RECOVid, 2020. Economic Effects of Covid-19 in Luxembourg - First RECOVid Working Note With Preliminary Estimates. Research Luxembourg, Covid-19 Task Force, April.

Snoeck, C.J., Vaillant, M., Abdelrahman, T., Satagopam, V.P., Turner, J.D., Beaumont, K., Gomes, C.P.C., Fritz, J.V., Schröder, V.E., Kaysen, A., Pavelka, L., Stute, L., Ramos Meyers, G., Pauly, L., Hansen, M., Pauly, C., Aguayo, G.A., Perquin, M., Hanff, A.-M., Ghosh, S., Gantenbein, M., Huiart, L., Ollert, M., Krüger, R., 2020. Prevalence of sarscov-2 infection in the Luxembourgish population: the CON-VINCE study. medRxiv.

Wilmes, P., Zimmer, J., Schulz, J., Glod, F., Veiber, L., Mombaerts, L., Rodrigues, B., Aalto, A., Pastore, J., Snoeck, C.J., Ollert, M., Fagherazzi, G., Mossong, J., Goncalves, J., Skupin, A., Nehrbass, U., 2021. Sars-cov-2 transmission risk from asymptomatic carriers: Results from a mass screening programme in Luxembourg. Lancet Regional Health - Europe 4. 